IZA DP No. 6244

Educational Upgrading and Returns to Skills in Latin America: Evidence from a Supply-Demand Framework, 1990-2010

Leonardo Gasparini Sebastián Galiani

Guillermo Cruces

Pablo Acosta

December 2011 


\title{
Educational Upgrading and Returns to Skills in Latin America: Evidence from a Supply-Demand Framework, 1990-2010
}

\author{
Leonardo Gasparini \\ CEDLAS-UNLP
}

Sebastián Galiani

Washington University in St. Louis

Guillermo Cruces

CEDLAS-UNLP, CONICET and IZA

Pablo Acosta

World Bank and IZA

Discussion Paper No. 6244

December 2011

\author{
IZA \\ P.O. Box 7240 \\ 53072 Bonn \\ Germany \\ Phone: +49-228-3894-0 \\ Fax: +49-228-3894-180 \\ E-mail: iza@iza.org
}

\begin{abstract}
Any opinions expressed here are those of the author(s) and not those of IZA. Research published in this series may include views on policy, but the institute itself takes no institutional policy positions.

The Institute for the Study of Labor (IZA) in Bonn is a local and virtual international research center and a place of communication between science, politics and business. IZA is an independent nonprofit organization supported by Deutsche Post Foundation. The center is associated with the University of Bonn and offers a stimulating research environment through its international network, workshops and conferences, data service, project support, research visits and doctoral program. IZA engages in (i) original and internationally competitive research in all fields of labor economics, (ii) development of policy concepts, and (iii) dissemination of research results and concepts to the interested public.
\end{abstract}

IZA Discussion Papers often represent preliminary work and are circulated to encourage discussion. Citation of such a paper should account for its provisional character. A revised version may be available directly from the author. 


\title{
ABSTRACT
}

\section{Educational Upgrading and Returns to Skills in Latin America: Evidence from a Supply-Demand Framework, 1990-2010*}

\begin{abstract}
It has been argued that a factor behind the decline in income inequality in Latin America in the 2000s was the educational upgrading of its labor force. Between 1990 and 2010, the proportion of the labor force in the region with at least secondary education increased from 40 to 60 percent. Concurrently, returns to secondary education completion fell throughout the past two decades, while the 2000s saw a reversal in the increase in the returns to tertiary education experienced in the 1990s. This paper studies the evolution of wage differentials and the trends in the supply of workers by educational level for 16 Latin American countries between 1990 and 2000. The analysis estimates the relative contribution of supply and demand factors behind recent trends in skill premia for tertiary and secondary educated workers. Supply-side factors seem to have limited explanatory power relative to demand-side factors, and are only relevant to explain part of the fall in wage premia for high-school graduates. Although there is significant heterogeneity in individual country experiences, on average the trend reversal in labor demand in the 2000s can be partially attributed to the recent boom in commodity prices that could favor the unskilled (non-tertiary educated) workforce, although employment patterns by sector suggest that other within-sector forces are also at play, such as technological diffusion or skill mismatches that may reduce the labor productivity of highly-educated workers.
\end{abstract}

JEL Classification: J2, D3, I2, O5

Keywords: $\quad$ skill premia, supply and demand of labor, income inequality, Latin America

Corresponding author:

Guillermo Cruces

Centro de Estudios Distributivos

Laborales y Sociales, Facultad de Ciencias Económicas

Universidad Nacional de La Plata

Calle 6 entre 47 y 48, 5to. piso, oficina 516,

B1900TEN La Plata, Provincia de Buenos Aires

Argentina

E-mail: gcruces@cedlas.org

\footnotetext{
* This document is a background paper for the report Skills for the $21^{\text {st }}$ Century in LCR, prepared by the World Bank, Human Development, Latin America and the Caribbean Region. The authors also acknowledge support from the CEDLAS-IDRC LaborAL (www.Labor-AL.org) project. The authors wish to thank continuous support by the report's coordinators, Cristian Aedo and lan Walker, and by Augusto De La Torre, Chief Economist for the World Bank, Latin America and Caribbean Region, as well as discussions and comments received from François Bourguignon, Michael Crawford, John Gilles, Francisco Ferreira, Gary Fields, Tim Gindling, Margaret Grosh, Julian Messina, Jamele Rigolini, and seminar participants in Washington, DC (World Bank), and Buenos Aires (LaborAL meeting and Banco Central). Javier Alejo, Santiago Garganta and Emmanuel Vázquez provided outstanding research assistance. All remaining errors are solely the authors'.
} 


\section{Table of contents}

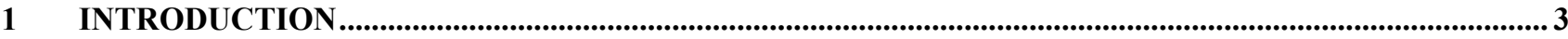

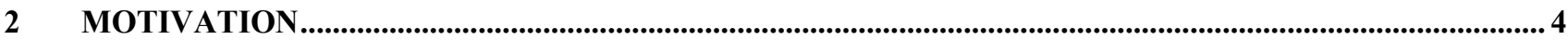

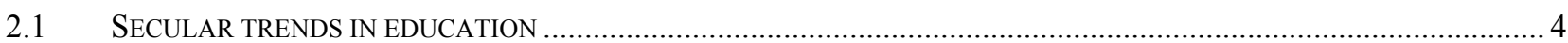

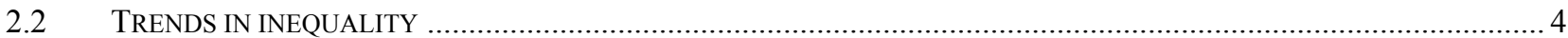

3 EVOLUTION OF THE WAGE SKILL PREMIUM IN LATIN AMERICA: APPROACH AND STYLIZED

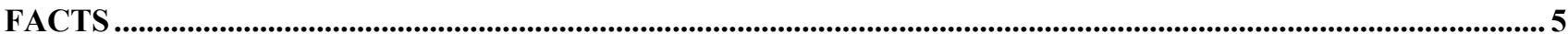

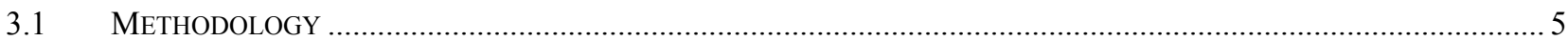

3.2 ESTIMATION OF WAGE SKILL PREMIA, RELATIVE SUPPLY, AND RELATIVE DEMAND FACTORS .......................... 8

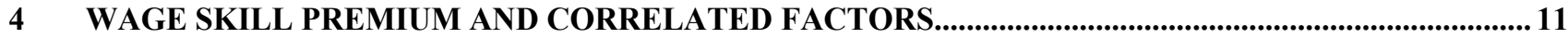

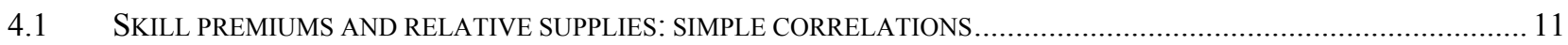

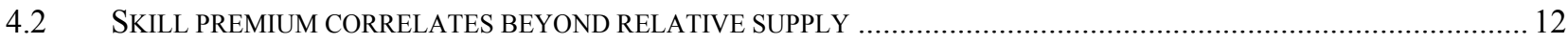

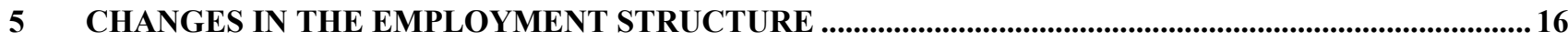

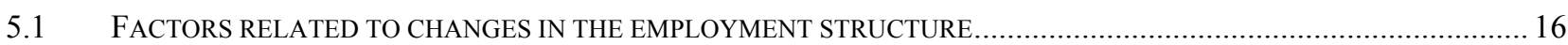

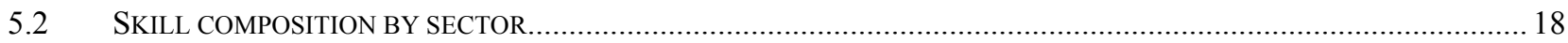

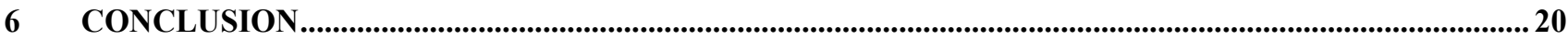

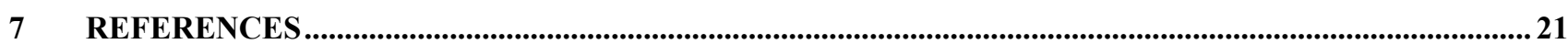

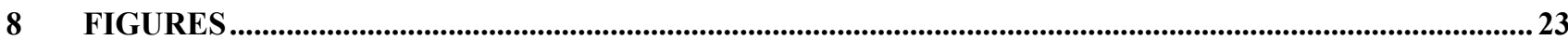

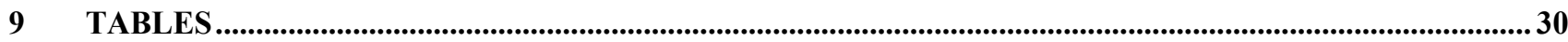

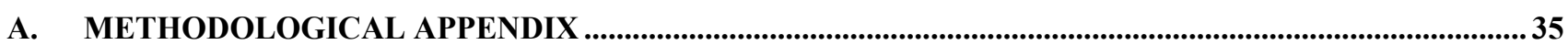

A1.BASIC KATZ AND MURPHY (1992) SUPPLY AND DEMAND FRAMEWORK WITH TWO INPUTS ….............................. 35

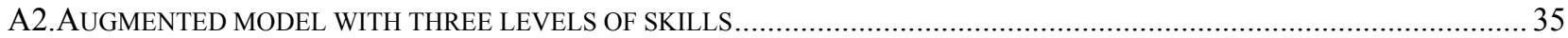

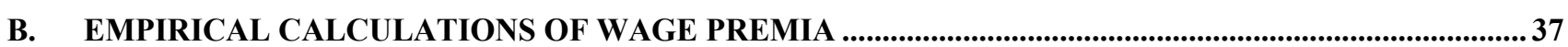

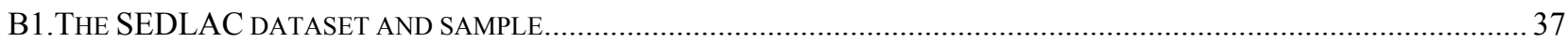

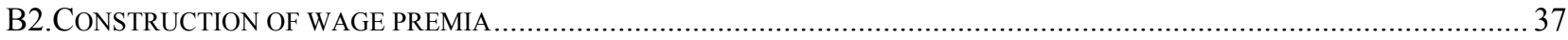

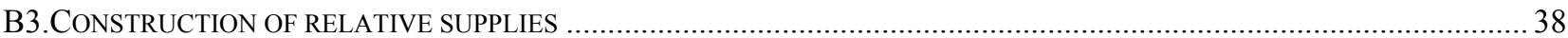

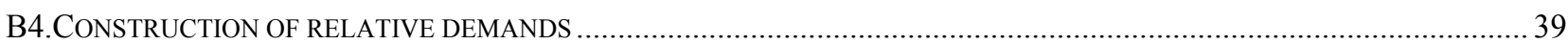

C. APPENDIX: EVOLUTION OF RELEVANT VARIABLES OVER TIME BY COUNTRY ........................ 40

C1.WAGE PREMIUMS, RELATIVE SUPPLY AND RELATIVE DEMAND: COUNTRY-SPECIFIC TRENDS.................................. 40

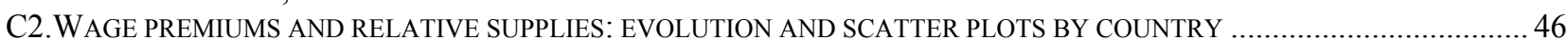

C3.WAGE SKILL PREMIUMS AND TERMS OF TRADE: EVOLUTION AND SCATTER PLOTS BY COUNTRY ............................50 


\section{Introduction}

The educational level of Latin America's population and its labor force has been increasing steadily since at least the second half of the $20^{\text {th }}$ century. However, this educational upgrading accelerated in the last two decades: while in 1990 the proportion of workers with at least secondary education was close to 40 percent, it increased to almost 60 percent by 2010 (Barro and Lee, 2010). It has been suggested that this educational expansion may have played a role in the recent evolution of income inequality in the region, operating through changes in returns to skills. In effect, while income inequality increased over the 1990s in most Latin American countries, the decade of 2000 was the scenario of a widespread and significant fall in most measures of socioeconomic and labor inequities (López-Calva and Lustig, 2010; Gasparini et al, 2011).

The purpose of this document is to establish which factors related to the demand and supply of labor by skill level can account for this differential evolution of inequality in Latin America, concentrating on the change in the distribution of labor earnings in terms of returns to skills. Abstracting from other factors related to income redistribution (e.g., fiscal policy, social and private transfers), this document conducts an analysis of the evolution of returns to skills and related factors for 16 countries in the region over the two decades. The analysis is based on a simple but illustrative supply and demand equilibrium framework that has been applied successfully to the study of returns to labor market skills in developed countries (Katz and Murphy, 1992; Goldin and Katz, 2007) as well as some developing countries (Montes Rojas, 2006; Galiani, 2009; Manacorda et al, 2010; Gallego, 2011). The methodology is based on a careful examination of changes in wage differentials and the relative supply of workers with different levels of educational attainment, from which consistent patterns in relative demand for skilled and unskilled labor can be derived, and through decompositions that illustrate the relevance of between and within sector factors behind changes in relative employment across types of labor.

The main results of the paper show that in a context of constant rise in the relative supply of skilled and semi-skilled workers, returns to secondary education completion fell throughout the last two decades, while the increase in returns to tertiary education experienced in the 1990s was reversed during the decade of 2000. Supply-side factors seem to have limited explanatory power relative to demand-side factors, and are only relevant to explain part of the fall in wage premia for high-school graduates. While there is significant heterogeneity in individual country experiences, the change in the labor demand trend for tertiary educated workers in the 2000 s can be partially attributed to the recent boom in commodity prices that could favor the unskilled (non-tertiary educated) workforce, although employment patterns by sector suggest that other within-sector forces are also at play, such as technological diffusion or skill mismatches that may reduce labor productivity of high-educated workers.

The rest of the document is organized as follows. The next section provides a motivation for the analysis by documenting briefly the secular expansion in education in the region and the trends in income inequality over the decades of 1990 and 2000. Section 3 in turn describes the basic supply and demand framework developed to account for changes in wage skill premium and the relative supply of workers with different skill levels. Section 4 examines the role of supply and proxies for demand factors in the evolution of regional aggregates by means of regression analysis. Section 5 
explores the changes in the structure of production and employment across sectors over the last two decades, and discusses their potential impacts on the relative demand for skilled labor and hence on employment and the skill premium. Section 6 presents some brief conclusions, while a series of methodological and data appendices complement the discussion and results presented in the body of the document.

\section{Motivation}

\subsection{Secular trends in education}

The stock of human capital is the main productive asset for households. As such, formal education constitutes one of the main determinants of an individual's income, and is arguably a key to a wide set of economic and social opportunities. Latin America has experienced substantial changes in the educational attainment levels of its labor force since the second half of the $20^{\text {th }}$ century, which even accelerated in the last two decades (see Figure 2.1). Now, one in eight workers have tertiary education (compared with one in thirteen in 1990), and nearly half of them has secondary education (compared with one third in 1990).

In terms of average years of education, Figure 2.2 illustrates the significant increase in experienced in all Latin American countries, by 1.5 years on average between 1989 and 2009 (Cruces et al., 2011). This increase can mostly be attributed to the expansion of secondary schooling, following the raise in primary school enrolment experienced in the 1960s-1980s (Figure 2.3). But despite a generalized upward trend in educational attainment of the labor force, there is still substantial heterogeneity between countries. Only a minority of countries has an average of more than 9 years of education for adults in the 25-65 age range - this group includes those in the Southern Cone (Argentina, Chile, Uruguay) and Panama - while some countries in Central America (Guatemala, Honduras and Nicaragua) present a much smaller figure, with an average below 6 .

The Gini coefficient for years of education has also been falling steadily for all countries in the region over the 1990s and the 2000s. This indicator, however, is not sufficient to signal an unambiguous reduction in inequality of education. While individuals from high and low socioeconomic strata have all seen their average levels of education increase, Cruces et al. (2011) report substantial differences for adults in the top quintile compared to those in the bottom quintile, in some countries representing as large as 7.5 years of difference. This quintile gap widened in almost all countries in the 1990s (except for Venezuela) and got smaller in most countries in the 2000 s. While the issue of whether or not inequality in education in the region has increased or not depends on which aspect and concept one attempts to capture, there is no ambiguity in the fact that average educational attainment has increased over time for all countries in the region.

\subsection{Trends in inequality}

In parallel to this educational expansion, there were also considerable changes in the patterns of income inequality in Latin America in the 1990s and the 2000s. Gasparini et al. (2011) indicate that by any account inequality is still a distinctive and pervasive characteristic of the region, with an 
average level of the Gini income coefficient for the latest figure available c. 2010 of around 50.6 among the highest in the world. Nevertheless, after a generalized increase in the 1990s, there is a sizeable downward trend in income inequality at the regional level that starts in the first half decade of the 2000s, as witnessed by the evolution of the Gini coefficient depicted in Figure 2.4, and also concurrent with a period of acceleration in economic growth and poverty reduction. Moreover, as documented in Gasparini et al. (2011), this downward trend is statistically significant, generalized within sub-regions of Latin America or any other country-weighting scheme, and robust to the choice of inequality indicator. Again, this regional trend reflects substantial changes at the country level: inequality only experienced a statistically significant decline in nine out of 17 countries in the region for the 2006-2009 period. $^{1}$

The multitude of policy changes, external shocks and country experiences imply that there is no single satisfying explanation for these trends, which can be attributed to a variety of factors distributional improvements in the 2000s may be due to realignments after the shocks and structural reforms of the $1990 \mathrm{~s}$, or to the favorable international scenario in terms of liquidity and commodity prices faced by the region in the second half of the 2000s. Moreover, these changes might be mediated in some cases by pro-poor and redistributive public policies - see the discussion in LópezCalva and Lustig (2010) and Gasparini et al. (2011). This paper explores one of the main channels that affect income distribution: changes in labor market returns to the educational level of the population, arguable one the main relevant factors given that wages are the main income source for most Latin American households.

\section{Evolution of the wage skill premium in Latin America: Approach and stylized facts}

\subsection{Methodology}

This section establishes an analytical framework to study changes in returns to education, and how to determine the relative contribution of supply and demand factors to the observed trends. As discussed by Bourguignon et al. (2005), it is possible that a "paradox of progress" emerges in the process of development: an equalizing increase in schooling may generate an unequalizing change in the distribution of labor income, which can be attributed to the presence of convexity in the returns to education - i.e., if the return to education increases at an increasing rate with the level of attainment.

Evidence of this first order effect can be established, for instance, by means of micro-decomposition exercises. This approach consists in deriving counterfactual distributions of individual earnings in a given period by assigning the distribution of education from another period, and comparing the observed and the counterfactual income distributions (holding all other factors constant - for instance, returns to education). Battistón et al. (2011) carry out this type of analysis for a number of countries in Latin America, and confirm the presence of this "paradox of progress": changes in education induced higher income inequality (through the highly convex structure of returns) in most countries in the region. The changes were more unequalizing in the 1990s than in the 2000s. These exercises are illustrative as a first order approximation, but they are intrinsically partial: the impact of

\footnotetext{
${ }^{1}$ The change was not significant or there was no updated information for the remaining eight countries.
} 
education on earnings also depends crucially on returns to human capital, which in this framework are assumed to remain unchanged as education expands.

However, the analysis of an educational expansion must take into account equilibrium effects in the labor market, and in particular the changes in the differential levels of remuneration by level of education that emerge from these equilibriums. Tinbergen (1975) provides a framework to interpret the role of labor supply and demand factors in changes in returns to education and in the evolution of the aggregate distribution of earnings. It discusses the role of a secular increase in the relative supply of skilled labor with respect to that of unskilled labor, postulating that such changes in supply should induce a reduction in the remuneration gap between the two groups - and consequently a fall in aggregate income inequality, given the salient role of human capital in household's income generating processes. An increase in the relative demand for skilled labor, however, might partially offset this equalizing impact of relative supply. Tinbergen's (1975) discussion is often referred to as "the race between education and technology", because he postulated that secular technological change would favor the relative demand for skilled labor, increasing its relative remuneration (and thus overall inequality), whereas educational upgrading would provide a counterbalancing force reducing this premium.

Tinbergen's framework has proved useful for discussing the evolution of inequality and its relationship to human capital accumulation over time. This framework has been formalized, among others, by Katz and Murphy (1992), Card and Lemieux (2001), and Golding and Katz (2007). Following these authors, it is possible to simplify the analysis of inequality, human capital and labor markets by assuming two factors of production, corresponding to two levels of skills among workers - high and low. Inequality is mainly driven by the remuneration differential between these two groups, the wage skill premium, which in turn is determined by an interaction of the relative supply of high skill to low skill workers (which proxies for changes in the human capital composition of the workforce), and the corresponding relative demand for these two factors of production. Changes in aggregate income inequality follow closely the evolution of this wage premium, since human capital constitutes households' main productive assets. In this simple supply and demand equilibrium framework, an increase in the relative supply of skilled workers should result in a fall in their relative remuneration, while a positive change in the relative demand for this type of workers would increase the wage skill premium.

Katz and Murphy's (1992) pioneer methodology has been applied to numerous country case studies in Latin America - for instance, for Mexico in the period 1990-2003 (Montes Rojas, 2006), Chile 1960-2000 (Gallego, 2011), and Panama 1980-2007 (Galiani, 2009). More recently, Manacorda et al. (2010) develop a full-fledged analysis of the relationship between changes in the wage skill premium and in the relative supply of skilled workers for Argentina, Brazil, Chile, Colombia, and Mexico in the 1980s and the 1990s. The authors adapted the formalization proposed by Card and Lémieux (2001) to a setting which distinguishes between unskilled workers (defined as those with up to primary education), semi-skilled workers (those with some secondary education - complete and incomplete) and skilled workers (those with some tertiary education). They document a substantial rise in the supply of workers with some secondary education, and they find a fall in the relative wage of this group with respect to unskilled workers, consistent with the large increase in their supply. 
They also find a simultaneous rise in the relative wages of skilled workers, which they attribute to a generalized shift in the demand for workers with tertiary education.

The basic framework in this paper assumes a production function with a constant elasticity of substitution (CES) and two factors, skilled and unskilled labor. ${ }^{2}$ Total output is a function of the quantities of these factors, of the elasticity of substitution between the two, and of other technology parameters. This basic CES production function can be augmented to accommodate three levels of skills by partitioning unskilled workers into two main sub-components. ${ }^{3}$ Following Goldin and Katz (2007), unskilled workers are aggregated into a composite factor consisting of a CES sub-aggregate with its own elasticity of substitution between the two unskilled groups. ${ }^{4}$ Adopting an educationbased measure of skills, skilled workers $(S)$ are defined as those with some tertiary education (either complete or not complete), while unskilled workers $(U)$ encompasses workers with a high school diploma or lower educational attainment. $U$ is in turn divided into two groups, which correspond to workers with a high school degree $(H)$ and those with a lower level of education (referred to as high school dropouts) $(D)$, respectively. ${ }^{5}$

Under perfect competition, with a large number of firms and factors paid at the marginal product value, the wage skill premium between skilled and unskilled workers $\left(w_{S} / w_{U}\right)$ and the differential between high school graduates and dropouts $\left(w_{H} / w_{D}\right)$ in year $t$ satisfy the following two relationships:

$$
\begin{aligned}
& \log \left(\frac{w_{S_{t}}}{w_{U_{t}}}\right)=\log \left(\frac{\lambda_{t}}{1-\lambda_{t}}\right)-\frac{1}{\sigma_{S U}} \log \left(\frac{S_{t}}{U_{t}}\right) \\
& \log \left(\frac{w_{H_{t}}}{w_{D_{t}}}\right)=\log \left(\frac{\theta_{t}}{1-\theta_{t}}\right)-\frac{1}{\sigma_{H D}} \log \left(\frac{H_{t}}{D_{t}}\right)
\end{aligned}
$$

where $\sigma_{S U}$ is the elasticity of substitution between skilled and unskilled labor, $\sigma_{H D}$ is the elasticity of substitution of the two sub-components of the unskilled composite factor, $S_{t} / U_{t}$ and $H_{t} / D_{t}$ are the corresponding relative supplies of these factors, and the first terms on the right hand side of each equations represent demand shifter parameters $\left(\lambda_{t}\right.$ and $\left.\theta_{t}\right)$. The skilled-unskilled wage differential

\footnotetext{
${ }^{2}$ For conciseness, details of the model are presented in the Methodological Appendix A.

${ }^{3}$ This setting follows Goldin and Katz (2007). The authors incorporate three levels of skills into their analysis, given the importance of secondary schooling in the United States in the first half of the 20th century. Manacorda et al. (2010) also distinguish three skill levels for their study on Latin American countries.

${ }^{4}$ Implicitly, this setup assumes some segmentation between skilled and unskilled workers. Manacorda et al. (2010) use a more flexible approach where the three types of labor are considered jointly instead of having an unskilled labor aggregate. These authors also construct different groups by age-potential experience. In both cases, they find that these distinctions make little difference to their results - for instance, they find that different age groups are virtually perfect substitutes. As argued by Galiani (2009) in his analysis of Panama, the model presented here (based on Goldin and Katz, 2007) is more parsimonious, and sufficient to study a higher degree of disaggregation within the labor force while maintaining a more tractable and intuitive estimation phase.

${ }^{5}$ Manacorda et al. (2010) consider semi-skilled workers as those with at least some post primary education, whereas in this study the middle group consists only of those with a high school degree. This is because, as opposed to Manacorda $e t$ al. (2010) who cover the decades of 1980 and 1990, this analysis covers the 1990s and the 2000s, a period with a higher prominence of secondary education in the region. In general, the underlying definitions in the literature correspond to categories more relevant for the countries and periods under study - for instance, Lindley and Machin (2011) study the differential between college graduates and those with a postgraduate degree in the United States and the United Kingdom in the period 1963-2009.
} 
captures the traditional Katz and Murphy (1992) college premium, while the second term represents the high school premium - the difference in wages within the two groups that constitute the unskilled aggregate. Large values for the elasticities of substitution $\sigma$ suggest that the two types of labor are close to perfect substitutes, and relative wages would then be uncorrelated with relative quantities.

The model from which these equations are derived captures the intuition of the Tinbergen's framework: for instance, the wage skill premium between skilled and unskilled labor will decline when the relative supply of skilled labor $S_{t} / U_{t}$ increases, and it will rise with positive changes in the relative demand parameter. Moreover, the greater the elasticity of substitution between two factors, the greater must be the fluctuations in their relative demand to explain any given time series of relative prices for a given time series of observed relative quantities.

A limitation of the Tinbergen framework and its subsequent applications, however, is that for all its emphasis on both supply and demand factors, it does not provide for an unambiguous way to approximate changes in demand. This limitation is due to the difficulty of identifying simultaneous demand and supply movements from observed quantities and prices which are, by definition, equilibrium points resulting from the intersection of the two corresponding curves. While the constructed supply and wage skill premiums also result from market equilibrium, it is plausible to argue that the supply index, based on population stocks, represents the actual relative supply. Katz and Murphy (1992) and the subsequent studies in this literature use observed wage premiums and relative changes in quantities of skilled and unskilled labor as measures of relative prices and supply, respectively, and then compute the changes to the relative demand of skilled labor as a residual - that is, as the figures that would be compatible with the observed changes in prices and supply for a given levels of the elasticity of substitution between both factors (see Appendix B).

\subsection{Estimation of wage skill premia, relative supply, and relative demand factors}

This section presents results using the approach described in the previous section for 16 countries in Latin America from 1989 to 2009. The analysis is based on a careful process to construct country and time consistent aggregate measures of labor supply and wages by skill level. ${ }^{6}$ The two wage skill premiums (left hand side terms on equations 1 and 2) and the relative supplies of labor (last terms on the right hand side) are constructed from household survey data for each country. Intuitively, the skill premiums are derived from wage differentials in Mincer-type wage regressions, while the relative supplies are weighted functions of the proportions of each group of workers in the population. $^{7}$

More specifically and following Katz and Murphy (1992), this study derives the relative supply $S_{t} / U_{t}$ by dividing the population of each country into 24 groups according to its educational level, gender, and potential experience, and then computes the average wage for all years with respect to the wage

\footnotetext{
${ }^{6}$ The specific details on the construction of these variables are presented in Data Appendix B.

${ }^{7}$ As in Manacorda et al. (2010), the whole population between 25 and 55 years old is used to construct our measures of labor, although all the results are qualitatively and quantitatively similar if the supplies are derived from those in the labor force, from those working, or from the proportion of total hours worked by each skill group. Manacorda et al. (2010) also find no qualitative difference when using these four alternative definitions of supply.
} 
of the largest group (in the last year of the sample). These relative wages constitute the weights to compute the supply for each group measured in efficiency units - Katz and Murphy (1992) developed this notion to try to add up workers in terms of comparable "college equivalent" units. These efficiency-adjusted labor supplies are then added for all skilled and unskilled workers, and their ratio (in logs) is the measure of relative supply in efficiency units. The relative supply of high school graduate workers with respect to dropouts is derived analogously. The two terms on the right hand side of both equations correspond to the log of these relative supply aggregates. The skill premiums, in turn, correspond to weighted sums of the coefficient for each educational category (primary, secondary and tertiary, each in turn divided into complete and incomplete) in a Mincer regression for each country and year in the sample (see Appendix B). The weights are given by the share of employment of individuals with a given educational level in a base period.

Table 3.1 presents results for the skilled-unskilled wage premium and relative supplies, as well as the "residual" estimates of relative demand (for different values of the elasticity of substitution). ${ }^{8}$ Figures 3.1 and 3.2 present aggregate correlates, all net of country effects (i.e., as deviations of each country's means). Although there is substantial heterogeneity in the experience of the 16 countries in our sample, some patterns are common to most economies in the region. The relative supply of skilled workers increased substantially and continuously over the two decades under analysis, and at approximately at the same average rate for the region, with few exceptions such as Bolivia and Peru in the 1990s and El Salvador in the 2000s. This sustained and remarkable education upgrading of the region's workforce is consistent with the trends in the population outlined briefly in Section 2 above.

The pattern for the wage premium in Table 3.1 exhibits more heterogeneity. The wage skill premium increased for almost all countries in the region during the 1990s (except Brazil), modestly in Chile, Costa Rica, Honduras, Panama, Paraguay, and Peru, but substantially more in the remaining countries in the sample. On the contrary, during the decade of 2000 the wage skill premium fell in all countries in our sample, with minor changes only in Costa Rica and El Salvador - the average rate of reduction was about 2.8 percent per year. The fall started in the late 1990s in some economies (e.g., Mexico) and later in other South American economies that experienced serious macroeconomic crises (e.g. Argentina, Paraguay, and Uruguay). The fall in the wage gap continued throughout the decade with no signs of reversion in the international economic crisis that started in 2008 . Moreover, in most countries the fall in the wage skill premium in the 2000s was enough to offset the increase of the 1990s, and in some countries the wage skill premium is lower at the end of the decade than in the early 1990s.

On average, thus, the wage gap between skilled and unskilled workers widened in the 1990s and shrunk in the 2000s, in the context of a seemingly secular increase in the relative supply of skilled workers (Figure 3.1). These patterns in wage skill premium and relative labor supply are consistent with a positive and strong increase in the relative demand for skilled labor in the 1990s in all countries, as witnessed by the estimates on residual demand presented in the last four columns of Table 3.1 and in the aggregate estimates in Figure 3.2. The estimates of relative demand for the 2000 s, consistent with the observed changes in relative supply and wage gaps, indicate a reversal in the trends of the previous decade. The indicators signal a negative shift in the relative demand for skilled labor in the 2000s, with the exception of Colombia and Costa Rica.

\footnotetext{
${ }^{8}$ Appendix C contains a detailed analysis of each country's specific evolution over time.
} 
Besides changes in relative remuneration between workers with some tertiary education and those with lower levels of education, the analysis also allows differentiating within the group of unskilled workers. The estimates decomposing the group of the unskilled into high school graduates and high school dropouts or less educated, are presented in Table 3.2. As described in Section 2, the supply of workers with secondary education increased with respect to that of workers with lower education levels for most countries and periods under study, with a only few exceptions - most notably, Mexico in the 2000s, with a slight decrease after strong growth in the 1990s. This secular increase was very large for some countries in the 1990s (Brazil, Chile, Colombia, El Salvador, and Mexico), while for others it was mostly in the 2000s (Argentina, Bolivia, Brazil, Chile, Panama, Paraguay, and Venezuela). Table 3.2 indicates a somewhat faster rate of expansion in the 2000s than in the 1990s.

These mostly uniform trends in relative supply of secondary school graduates with respect to high school dropouts, however, did not translate into common trends in the relative remunerations of the two groups, with a diversity of country experiences. During the 1990s, the wage differential between high school graduates and dropouts increased moderately in Argentina, Chile, and Peru, remained more or less constant in Venezuela, Colombia and Nicaragua, and fell in Bolivia, Brazil, Costa Rica, El Salvador, Honduras, Mexico, Panama, Paraguay, and Uruguay. The increase in the relative supply of high-school graduates in the 2000s was concurrent with a fall in the relative remuneration of this factor in most countries, with the exception of negligible changes in Argentina and Nicaragua, and increases in Costa Rica, Honduras, and Uruguay. It should be noted that the relative supply of high school graduates fell in the 2000 s for the last two countries in the list. The relative wage of high school graduates with respect to the dropout group fell during the two decades in Bolivia, Brazil, El Salvador, Mexico, Panama, and Paraguay.

The results in Table 3.2 and Figure 3.1 indicate that on average, concurrent with a sharp rise in the supply of high school graduates with respect to dropouts during last two decades, the average wage differential between the two groups modestly fell in both periods (albeit more strongly in the 2000s). These patterns are consistent with an increase in relative demand for high school graduates with respect to dropouts, although at a lower pace than the increase in their relative supply (Figure 3.2). Still, average masks important country differences. In Brazil, the continuous increase in the relative supply of high school graduates and falling skill premium implied only a modest role for relative demand factors, while in other countries (Argentina in the 2000s, Chile in the 1990s) demand factors seem to be the driving force keeping wage differentials down in the context of secular growth in the relative supply.

Since labor income is the main income source for households in Latin America, it is expected that changes in wages by skill level have important implications for overall income inequality. Figure 3.3 depicts the evolution of three indicators: the Gini coefficient of per capita household income; the skilled-unskilled wage premium; and the high school-dropout differential wage differential, for all countries and net of country-effects (i.e., as deviations of each country's means). The fitted trend in the first panel, which depicts the evolution of the Gini coefficient, is broadly consistent with the aggregate trend presented in Figure 2.4: income inequality rose in the 1990s in Latin America, and fell in the 2000s. This inverted $U$ shape is remarkably similar to that of the fitted line in the second panel, which depicts the evolution of the skilled-unskilled wage premium. The high school premium in the bottom panel, however, has constant declining trend over the two decades under analysis. 
The relationship between overall income inequality and wage differentials by education level, posed in the Tinbergen/Katz and Murphy literature, is further confirmed by the evidence in Figure 3.4, which presents scatter plots of the Gini coefficients with respect to the two wage differential variables. The fit is better for the aggregate skilled-unskilled wage differential, although the relationship between the Gini and the high school premium is still positive and strongly significant. Taken together, the evidence in Figures 3.3 and 3.4 suggests that the wage skill premiums are useful proxies for aggregate levels of inequality, and furthermore, that explaining the evolution of these differentials should prove useful for interpreting broader distributional changes in these economies.

\section{Wage skill premium and correlated factors}

\subsection{Skill premiums and relative supply: Simple correlations}

This section studies further some of the correlations that emerged from the descriptive analysis of the previous section. The methodology is based on Katz and Murphy's (1992) study for the United States, which developed a series of time series regressions of the wage skill premium as a function of the relative supply of skilled labor and other factors. Here, and also following Manacorda et al. (2010), pooled data from all the countries in the sample are used. The advantage of pooling the data for the region is that it allows the inclusion of countries for which the limited number of years is not suitable for a country-specific regression. The results, thus, should be interpreted as reduced form estimates of averages for the whole region, with the caveat that the aggregate patterns described above do not necessarily correspond to all the 16 country experiences. ${ }^{9}$

The wage skill premium regressions a la Katz and Murphy (1992) attempt to establish the comparative relevance of supply and demand factors. In this framework, however, there is no unambiguous indicator of relative demand, and the literature for the United States has thus proxied these factors by adopting different specification of time trends. These are expected to capture shifts in the relative demand for skilled workers, and this approach has been adopted by most recent studies (Goldin and Katz, 2008; Acemoglu and Autor, 2010, among many others). The conjecture that time trends might capture adequately the shifts in relative demand seems to obey to the implicit assumption that the driving force behind these shifts is a relatively steady trend determined by cumulative factors, such as technological change. This assumption, however, does not seem to suit the nature of changes in Latin American economies. While technical change is probably a relevant force behind the demand for skilled labor in the region, a multitude of other factors might be expected to play a role, either directly mediating the forces of technological change (for instance, through relative prices of technology embedded in capital) or indirectly - for instance, external shocks, macroeconomic crises and the ensuing devaluations (which affect the relative price of capital with respect to labor), structural reforms (such as trade liberalization and privatizations, with direct effects on employment and demand for skills), and policy reversals. These types of events, more common in Latin American economies than in the advanced countries traditionally studied in Katz

\footnotetext{
${ }^{9}$ Given the large differences in population and size of the economies, the results are presented as unweighted country averages.
} 
and Murphy-type of analysis, imply that time trends might be unable to capture the potential changes, swings and reversals in the pattern of relative demand for skilled labor.

With these limitations in mind, the analysis here follows Manacorda et al.'s (2010) approach, where no explicit proxy for relative demand is included. Instead, country and year fixed effects (or time trends) capture the demand shifters in the right hand side of equations (1) and (2) above. The regressions for the college wage premium have the following form:

$$
\log \left(\frac{w_{S}}{w_{U}}\right)_{c t}=\alpha+\beta \log \left(\frac{S}{U}\right)_{c t}+\sum C_{c}+\sum T_{t}+\varepsilon_{c t}
$$

where the left hand side variable is the wage skill premium in year $t$ for country $c$, and the right hand side variables are a constant, the relative supply of skilled labor, and country $(\mathrm{C})$ and year $(\mathrm{T})$ fixed effects. The regressions for the high school premium are defined analogously, with this indicator as the dependent variable and the corresponding relative supply as the main correlate.

The results for these specifications are presented in Table 4.1, columns 1 to 3, while the regressions with the high school premium as the dependent variable are presented in Table 4.2. As it could be expected from the aggregate patterns in Figure 3.1 (and from the country-specific scatter plots in Figures $\mathrm{C} 3$ and $\mathrm{C} 4$ in the appendix), the simple correlations between the levels of the wage differentials and the respective relative supplies are negative and strongly significant, even when including country fixed effects (columns 1 and 2). However, once year effects and standard errors are clustered by country to account for serial correlation and other interfering effects, only the coefficient of the relative supply of high school workers in Table 4.2 remains statistically significant at the usual levels throughout all the specifications. ${ }^{10}$ This point estimate is relatively low, suggesting a large elasticity of substitution between high school graduates and dropouts in the production function.

This evidence is compatible with the Tinbergen framework and the Katz and Murphy (1992) results for the United States: the educational upgrading of the labor force, manifested through the increase in the relative supply of workers with some college education or with a high school degree, implied by themselves a fall in their relative remunerations over the decades of 1990 and 2000. Moreover, the effect seems to have been stronger for the skilled-unskilled wage premium than for the high schooldropout differential.

\subsection{Skill premium correlates beyond relative supply}

The analysis so far concentrated on the impact of relative supply on wage skill premiums. The time and country fixed effects in the regressions were implicitly assumed to capture the evolution of relative demand - the first terms on the right hand side of equations (1) and (2). However, there are theoretical reasons to include at least two types of variables in regressions such as those performed in this Section. On the one hand, other factors, such as institutional arrangements and the business cycle, might be expected to have a direct impact on the wage skill premium. On the other hand, it is also possible that some specific variables might influence the relative demand for skilled labor

\footnotetext{
${ }^{10}$ Results are very similar when including linear and quadratic time trends instead of year fixed effects
} 
directly - while not capturing the whole fluctuation of demand, these variables might still constitute valid proxies for some of the variability in labor demand.

With respect to the first group of variables, cyclical labor market conditions might affect skilled and unskilled workers differently, and these differences might in turn alter the structure of remunerations in the economy. Autor et al. (2008), in a similar analysis for the United States, include the prime age male unemployment rate in their regressions to capture the potential effect of these fluctuations. In the regressions discussed below, the aggregate unemployment rate is included, but also (in separate specifications) the unemployment rate of the two skill groups being compared (either skilledunskilled or high school-dropouts). The intuition is that, besides aggregate cyclical fluctuations, these distinct indicators might better capture a "wage curve" effect, whereby higher unemployment for a specific group is related to lower wage levels for this group (for instance, after structural reforms such as privatizations of state-owned enterprises). Differential unemployment rates might thus be expected to affect remuneration gaps between skill groups.

Institutional and political factors can also play a role in determining wage differentials. Autor et al. (2008) include the real value of the minimum wage as one of the independent variables in their regressions. The minimum wage is a salient feature of the discussion of inequality and wage differentials in the literature for the United States (DiNardo et al., 1996; Lemieux, 2006), and the authors use this variable as a proxy to capture the potential impact of labor market institutions on the wage skill premium. In developed economies, the minimum wage has almost universal coverage (i.e., most workers are subject to this legislation), but it is binding mostly for young and less educated worker. By raising the remuneration of workers at the bottom of the skill/education distribution, a binding minimum wage should have a negative relationship with the wage skill premium. However, this is not necessarily the case in Latin America because of the high levels of informality in the labor force. Despite the potential presence of "lighthouse" effects, whereby a change in the legal minimum wage affects even those outside the coverage or the reach of the legislation (Gindling and Terrell, 2005), and composition effects (Boeri et al., 2011), a substantial fraction of the workforce might not be effectively covered by the minimum wage. Moreover, formal salaried workers are not necessarily those at the bottom of the skill distribution in the region, and even if only a small fraction of skilled workers are at the minimum wage level, collective bargaining agreements indexed by the minimum wage might still imply that their remuneration follows changes in the minimum wage. The following exercise attempts to shed some light on these potentially conflicting effects in Latin America by including in the regressions an index of minimum wage levels by country. It should be noted, however, that these are not necessarily good indicators for the overall "pro-labor" environment. Manacorda et al. (2010) include a labor market reform index in their regressions; however, this series is not available for the whole period and all countries covered here. Unfortunately, there also is very little and unreliable information on union coverage in the region. $^{11}$

Finally, besides these cyclical and institutional features, a series of factors might also have an effect through changes in the relative demand for skilled labor. The most salient factors are both related to international trade. On one hand, there is an ample literature on the distributional effects of trade

\footnotetext{
${ }^{11}$ See McLeod and Lustig (2011) for a multi-country discussion of political factors behind the recent fall of inequality in Latin America.
} 
liberalizations in developing countries (Goldberg and Pavcnik, 2004; 2007) and for Latin America in particular. $^{12}$ The literature for the region indicates, in general, that trade liberalization had a significant but relatively small impact on skill premia, widening the wage skill gap and increasing inequality in the income distribution as a whole, although these effects typically explain only a relatively small fraction of the total increase in the skill premium. An important issue that needs to be established on a case by case basis is the factor of production that represents each country's comparative advantage with respect to its trade partners, and will thus benefit from trade liberalization - either non-renewable resources or unskilled labor, for instance. ${ }^{13}$ Besides these direct effects of trade openness, trade can also be a factor in the incorporation of capital goods complementary to skilled labor and thus introduce skill biased technical change (Acemoglu, 2003; Yeaple, 2005), which is also compatible with the evidence on the relationship between wage skills gaps and imports of machinery and equipment in the region (Acosta and Gasparini, 2007), as well as with exports (Brambilla et al., 2011). Because of the relevance of direct and indirect effects of trade on the wage skill premium, an index of average tariff levels is included in the regressions. ${ }^{14}$

While trade reforms where important in the 1990s in Latin America, there were relatively less policy changes in this area during the decade of 2000s. But a more salient feature of the decade of 2000s in Latin America was the growing importance of exports in the midst of a boom in commodity prices (Baffes and Haniotis, 2011) and in the context of the emergence of new trade partners for the countries in the region, most notably China (De La Torre et al., 2011). Changes in terms of trade, were not homogeneous across the region - while they increased on average during the 2000 s for South American countries and Mexico, they decreased for those in Central America. ${ }^{15}$ The regressions discussed below incorporate an index of "net barter terms of trade" (source: World Bank World Development Indicators) to capture the average effect of the recent evolution of international prices in the region, although it is possible that these average effects mask the heterogeneity of

\footnotetext{
${ }^{12}$ See for instance Galiani and Sanguinetti (2003) and Galiani and Porto (2010) for Argentina; Ferreira, Leite and WaiPoi (2007) for Brazil; Gill and Montenegro (2002) for Chile; Attanasio et al. (2004) for Colombia; and Harrison and Hanson (1999) for Mexico.

13 Even if a country has a comparative advantage in terms of unskilled labor, inequality can increase after trade liberalization. Atolia (2007) develops a dynamic Heckcsher-Ohlin model in which increasing inequality arises from trade liberalization in the short run because of asymmetric speeds of adjustment between the export and import sectors. The asymmetry generates a transitory capital accumulation that increases the relative wages of skilled workers because of capital-skill complementarity in production.

${ }^{14}$ The authors are grateful to Miguel Szekely for sharing his series of tariffs for the region.

${ }^{15}$ Galiani et al. (2011) study the distributive effects of terms of trade shocks. In their model, besides a non-tradable good, there are two tradable goods, one intensive in natural resources and another - an industrial good, for instance - intensive in unskilled labor. As in a typical Dutch disease model, an increase in the international price of the natural resourcesintensive good induces higher demand (and higher prices) for the non-tradable good, and a re-allocation of resources away from the production of the importable industrial good. The key to the distributional conflict within this model is the factor intensity in the production of the tradable industrial good and of the non-tradable good, and the composition of the consumption basket of the skill groups in terms of the three goods in the economy The model also highlights how these shocks introduce incentives for seeking compensation (for instance, by means of export taxes and transfers). This potential role of the tax system to cushion the impact of terms of trade shifts and re-distribute their effects reinforces the case for analyzing the country-specific political factors and the way in which the state mediates the diffusion of these shocks within the economy.
} 
country-specific cases, given the wide variety of economic structures in Latin America in terms of the factor intensity and the weight of the industrial, commodities and non-tradable sectors. ${ }^{16}$

The regressions incorporating these additional covariates are presented in columns 4-10 of Tables 4.1 and 4.2. ${ }^{17}$ The regressions in columns 7 and 8 also include a series of additional control variables to those described before, such as GDP per capita and the real exchange rate against the US dollar (both from World Bank World Development Indicators). These variables are included as a specification robustness test only, since there is no clear theoretically basis to assess their impact on wage skill differentials. The main result shows that after considering these additional variables and specifications, the coefficient on the relative supply of skilled labor in Table 4.1 becomes statistically insignificant. For the case of high-school graduates vs. dropouts, the coefficient on relative supply of workers remains statistically significant (except in column 10), indicating that supply side factors are more relevant to explain the evolution of high-school wage premia rather than tertiary educated (skill) premia.

Regarding the rest of covariates, aggregate unemployment rate has a positive relationship with the two wage differentials, although it is only significantly different from zero in just a few specifications of the skilled wage premium - that in column 8, which incorporates a series of additional macro variables as controls, and that in column 10, which restricts the sample to the nine countries with a long time series (see the note in the respective tables for details). However, including separate rates for skilled and unskilled workers, as in column 6 in Table 4.1, indicates that the unemployment level for unskilled workers does have a positive correlation with the wage skill premium, suggesting that a wage curve-type of effect might depress the remuneration levels of unskilled workers more than that of skilled workers. There is no significant effect for the separate high school and dropout unemployment rate in Table 4.2.

Tables 4.1 and 4.2 also present evidence on the potential impact of minimum wages on the skill premium. The regressions in column 8 of Tables 4.1 and 4.2 include an index of minimum wage levels for each country as a dependent variable, available from 1995 onwards. ${ }^{18}$ The results for the whole period under analysis indicate a negative but not statistically significant relationship between the level of minimum wages and the skilled-unskilled premium in the region, whereas the relationship is unexpectedly positive (though also not significantly different from zero) for the high school-dropout wage differential.

\footnotetext{
${ }^{16}$ Net barter terms of trade index is calculated as the percentage ratio of the export unit value indexes to the import unit value indexes, measured relative to the base year 2000. Unit value indexes are based on data reported by countries that demonstrate consistency under UNCTAD quality controls, supplemented by UNCTAD's estimates using the previous year's trade values at the Standard International Trade Classification three-digit level as weights. To improve data coverage, especially for the latest periods, UNCTAD constructs a set of average prices indexes at the three-digit product classification of the Standard International Trade Classification revision 3 using UNCTAD's Commodity Price Statistics, interna-tional and national sources, and UNCTAD secretariat estimates and calculates unit value indexes at the country level using the current year's trade values as weights.

17 Bearing in mind the limitations of this type of cross country regressions and to avoid spurious correlations, the regressions should not be interpreted as estimating causal effects but only as multivariate correlates of the wage skill differentials.

18 The authors are grateful to Tim Gindling for providing the index of real minimum wage levels (based on ILO estimates) for the countries under analysis.
} 
With respect to the trade-related variables, the coefficient of the tariff index is positive for both dependent variables, as expected, although it is not significantly different from zero (not reported). The most notable result from Table 4.1 is the negative and consistently significant correlation of the skilled-unskilled wage differential with the net barter terms of trade variable. ${ }^{19}$ This is consistent with a situation in which the boom in commodities benefited disproportionately unskilled labor in most countries in the region. This result is also robust to alternative changes in specifications presented in Table 4.1: whether adding additional covariates, such as tariffs or minimum wages, including additional control variables, excluding outliers in terms of trade such as Chile and Venezuela (mining and oil-based economies respectively, that experienced notable gains in terms of trade), or using just the nine countries with relative long time series. This average result for the region, however, masks some heterogeneity in terms individual country cases, as shown by the country-specific trends in the premiums and terms of trade variables (Figure C5) and in the scatter plots of premiums versus the price variable (Figures C6 and C7, respectively). ${ }^{20}$ For the case of highschool graduates vs. dropouts, changes in terms of trade do not have a significant predictive power on wage differential evolution.

This evidence shows that supply-side factors can explain very little of the observed evolution of wage premia by skill level, and are slightly more relevant for the case of high-school graduates vs. dropouts than for tertiary educated workers vs. the rest. It provides further support to demand-side hypotheses as being more relevant to explain these remunerations trends. Among several competing hypothesis, the role of terms of trade seems to be a promising one for the case of skilled-unskilled wage differential, though it is certainly not a "smoking gun" - the single factor responsible for the substantial decline in the relative demand for skilled labor in the 2000s. For that to be true, it should be concurrent with an increase in the use of unskilled labor in the region, and in a shift of labor towards the sectors in the economy producing the tradable goods that benefited from the international price increase. The analysis in the following section studies the sector composition of employment in order to establish whether this has been the case.

\section{Changes in employment structure}

\subsection{Factors related to changes in employment structure}

The previous sections have highlighted that the expansion of workers with secondary and tertiary education has been more or less steady in the decades of 1990 and 2000, but that it played a very limited role in explaining the drastic changes in labor market returns to education in Latin America (though perhaps it is a bit more factor for changes in returns to secondary education). Other unskilled-biased labor market policy interventions, such as changes in legal minimum wages, seem to neither be a relevant factor. By logic then, labor demand factors should be the main driver for changes in wage premium evolution in the region in the 1990 s and the 2000 s.

\footnotetext{
${ }^{19}$ For all specifications in Table 4.2, the relationship between terms of trade and high-school wage premium is negative but not statistically significant, and substantially lower in value than that of Table 4.1, with the exception of that in column 9 which excludes Chile and Venezuela (the outlier cases in the increase of terms of trade) from the regressions.

${ }^{20}$ The fact that the correlation is positive for some countries seems to indicate that other factors, such as factor intensity, government intervention, etc, might be operating as well.
} 
Several hypotheses may be behind changes in relative demand for skills. A first explanation is related to changes in output by sector of activity. Latin American economies have registered important shifts in the structure of production by sector in the last two decades. In the 1990s, almost all countries in the region experienced a drastic transformation of their economies, coincidentally with a period of trade liberalization, privatization, and modernization of their economies. As a consequence, the region experienced a surge in the importance of service sectors at the expense of agriculture and manufacturing, except in Central America where the "maquila" model gained ground and thus revitalized the manufacturing sector (see Figure 5.1). In contrast, during the 2000s, most of the countries shared an increase in the size of the mining and construction sectors, notably in the Andean countries, a situation exacerbated by the growing importance of China in the world economy, and the surge in the demand for natural resources that favored their terms of trade (as discussed in the previous section). For the rest of the sectors, the situation has been dissimilar: a) in the Southern Cone (Argentina, Paraguay, Uruguay), there was a reversal towards agriculture thanks to benign terms of trade from world commodity prices; b) while most countries continued their deindustralization process, Argentina and Uruguay were again the exception with a slight recovery of the sector; and c) services declined its relative importance in the region to make room for other sector expansions, except in Central America where it continued an upward trend (notably in Costa Rica and Panama).

These changes in the structure of production and employment could be generated, in turn, by various factors such as trade and industrial policy, and the evolution of international prices (terms of trade). An expansion of an unskilled-intensive industry may act as a positive factor demand shifter for unskilled labor. In terms of employment, these trends should be reflected in an increase in the use of unskilled labor and a shift towards sectors employing unskilled workers most intensively. The previous section showed that terms of trade can explain part of the observed evolution of changes in skill wage premia (just for tertiary workers), potentially operating through changes in the structure of production.

The second explanation is related to technological change. Information and communication technology may have required sophisticated skills to operate them in the 1990s and thus could have initially been more complementary to high-skill workers (see Acosta and Gasparini, 2007, for the case of Argentina), but technological diffusion to a larger population group may in part explain the trend reversal in the demand for skilled labor. If this is the case, firms would no longer pay a high premium for technology-related knowledge. The evidence for some countries in the region indicated a generalized increase of the use of skilled labor within all sectors in the 1990s, which can be interpreted as a manifestation of skill biased technological change (see for instance Gasparini and Cruces, 2010, for Argentina).

Finally, it is also possible that skill mismatches in the labor market are playing a role as well. The limited progress achieved in terms of school results as measured by standardized tests in Latin America suggests that the fall in returns to education may be related to deficient educational quality (as measured by international test scores such as PISA) (World Bank, 2011). This would imply that additional years of education did not necessarily improve workers' general knowledge and skills. Alternatively, the skills provided in the formal education sector may be of relatively good quality but may not be those most needed in the labor market. Employers' surveys in the region already identify 
that the majority of firms have increasing difficulties in finding workers with the right set of skills, in particular technical skills (World Bank, 2011).

This section will provide additional evidence on the role of demand as a major determinant of the evolution of the skill premium in Latin America in the 2000s. While proper discrimination among competing hypotheses would require deeper country-level research out of the scope of this paper, especially in terms of political and institutional factors, this section attempts to disentangle whether between-industry factors associated with changes in output and employment patterns across industries with different skill intensity dominate labor demand shifts in the majority of countries. Alternatively, a prevalence of within-industry changes in the composition of skilled and unskilled labor within sectors would favor hypotheses related to technological change or to the presence of skill mismatches in the labor market.

\subsection{Skill composition by sector}

To characterize the source of labor demand patterns, a decomposition of changes in the share of each type of labor in total aggregate labor is carried out. Following Katz and Murphy (1992), it is possible to define:

$$
\Delta\left(\frac{E_{k}}{E}\right)=\underbrace{\sum_{j} \alpha_{k j t} \Delta \theta_{j}}_{\text {BetweenEffect }}+\underbrace{\sum_{j} \theta_{j t^{\prime}} \Delta \alpha_{k j}}_{\text {WithinEffect }}
$$

where $E$ is total labor input (in efficiency units), $j$ indexes the economic sectors, $\alpha_{k j t}=E_{k j t} / E_{j t}$ is input $k^{\prime}$ s share of total employment in sector $j$ at the base year $t$, and $\theta_{j t}=E_{j t} / E_{t}$ is the participation of sector $j$ in total employment, also at time $t$. In order to implement these sector decompositions, ten aggregate sectors are used in each country: a) primary activities (agriculture, forestry, fishing, mining and quarrying); b) low technology manufacturing industries (food, beverage and tobacco, textile and clothing); c) other manufacturing industries; d) construction; e) retail and wholesale trade, repair, accommodation and food services; f) electricity, gas and water supply, transport and communication; g) financial sector, insurance sector and professional services; h) public administration and defense; i) education and health; and j) domestic services.

The first term of the decomposition, the "between effect", captures the impact of transformations in the sector structure of employment on the relative employment of a given factor (in this case, skilled labor). Suppose that, triggered by changes in international prices, sector $m$ expands while sector $n$ shrinks. If sector $m$ is skilled-intensive while sector $n$ is the opposite, the change in the structure of the economy (in terms of sector employment) would favor skilled labor. The second term, the "within effect" captures changes in employment due to variations in the intensity of use of different types of labor within each sector. This methodology, however, does not account directly for the evolution of labor demand by level of skill, but only changes in equilibrium quantities. There might be exogenous sources of changes in both between and within factors, but also changes driven by changes in factor prices. However, the between effect should be mostly driven by exogenous changes in the sector structure of the economy, while the within effect should captures exogenous factors such as biased technological change, but also adjustments of relative factor use to change in factor 
prices, most notably non-neutral technical change. This conjecture leads Katz and Murphy (1992) and subsequent contributions to directly measure between and overall effects, and obtain the within component as a residual.

Table 5.1 and Figure 5.2 present the full decomposition for a subset of countries with data that spans over the whole two decades. The first panel in Table 5.1 shows changes in the relative employment of tertiary educated workers ("skilled"), high-school graduates, and high-school dropouts. The next panels present the decompositions in between and within employment effects. A first observation is that the share of tertiary educated workers in total employment increased in all economies over time, consistent with the evidence presented before on educational upgrading in the region. On average, the proportion of tertiary educated workers increased by 0.6 percent per year in Latin America in the $1990 \mathrm{~s}$, and by 0.7 percent in the 2000s. The opposite happens with the share of workers with less than complete secondary education, which declined by 0.9 percent per year in the $1990 \mathrm{~s}$, and 1.1 percent in the 2000s. In the Southern Cone (Argentina, Chile), and El Salvador, the speed of the educational upgrading process of workers was higher in the 1990s, but in the rest, notably in Brazil and Nicaragua, it was much higher in the 2000s. Consistent with the patterns discussed in Sections 2 and 3, the proportion of high-school graduate workers also increased, albeit at a smaller pace than tertiary workers $(0.3$ percent per year in the $1990 \mathrm{~s}$, and 0.4 percent in the $2000 \mathrm{~s})$.

The decompositions suggest that both changes in the structure of the economy across industries, and changes in the relative use of different types of skill labor within industries contributed to the increase in the relative employment of skilled tertiary educated workers in both decades. In general, the within-sector effect explains most of the increase in relative tertiary educated employment creation, and dominates the between-sector effect, with the exception of Mexico in the 1990s (that opened up to NAFTA in 1994, the trend-reversal year in wage premium evolution) and Chile in the 2000s. As mentioned before, this may be related to the surge in services in the 1990s at the expense of other sectors that may have required an additional need for more qualified workers. In the 2000s, Brazil, Chile, Costa Rica and El Salvador experienced important between-sector employment effects, in particular in favor of tertiary educated workers, maybe associated with the expansion of hightechnology sectors and attraction of foreign direct investment during the period. For the rest, the within-sector changes dominate, in countries that mostly expanded in sectors related to agriculture or natural-resource based which typically do not create substantial employment reallocation and are mainly driven by external demand. Overall, the between-sector effect seems to explain about 20 percent of the increase in employment of tertiary educated workers in both 1990s and 2000s. Among high-school educated, between effects explain nearly a quarter of the relative employment of this type of workers in the 1990s, but for the 2000s virtually all changes in employment are explained by within-sector effects.

Therefore, most of the observed increase in skilled employment in the 2000s obeys within-industry skill upgrading. There does not appear to be a massive shift of employment between sectors, which suggests that factors such as changes in terms of trade can only at most a fifth of the observed change in employment by educational level. These results reinforce the idea that other concurrent factors are in play and there is no single reason for the change in the pattern of labor demand by skill level in the 2000s in Latin America. Other explanations must be invoked to explain the simultaneous decline in the price of more educated workers and the increase in their share of employment across most 
sectors. Technological diffusion or skill mismatches could have also played a role in determining the evolution of returns to education, and should be subject to further research to determine their relative importance.

\section{Conclusion}

This paper studied the evolution of wage differentials and trends in the supply and demand of workers by skill level (as proxied by educational attainment) for 16 Latin American countries over the decades of the 1990s and the 2000s. All countries in the region experienced a noticeable increase in average educational attainment, although the changes were not uniform across countries and socioeconomic groups. Wage skill premia and income inequality, on the other hand, started to fall consistently in the 2000s in almost all Latin American countries, reversing a two-decade increasing trend marked by the macroeconomic crises of the 1980s and the market oriented reforms of the 1990s.

This paper disentangled the relative contribution of supply and demand factors in explaining wage premia evolution. In a context of constant increase in the relative supply of skilled and semi-skilled workers, Tinbergen's framework suggests that differential evolution indicates a strong shift in demand towards skilled labor in the 1990s and a deceleration of this relative demand in the second period. This interpretation of the evidence is consistent with some country-specific studies which highlight the importance of privatizations, trade openness and other structural reforms during the 1990s in facilitating skill biased technical change and, more generally, spurring the demand for skilled labor.

Overall, his study shows that rising supply of educated workers can only explain a fraction of the observed movements in wage premia, and only for the case of high-school graduates. Changes in labor regulations, such as legal minimum wages, also exhibit limited explanatory power. In terms of demand-side factors, while there is significant heterogeneity in individual country experiences, for the case of tertiary educated workers ("skilled") the shift can partially be attributed to the recent boom in commodity prices, although the patterns of employment by sector suggest a significant role for other forces.

The reduced forms estimated in this paper, while suggestive, cannot establish the specific channels behind changes in labor demand. They do however indicate the direction for further research at the country-case level. The future research agenda should establish the relative role of the petering out of the unequalizing effects of the reforms of the 1990s, technological diffusion, political forces, government interventions (such as minimum wages) and changes in international prices. Regarding the latter, country-case studies should establish the direct effect of changes in terms of trade (through the structure of production and relative labor demand), and also their impact on government finances and the scope for redistributive policies. The analysis could also be based on alternative measures of skills in the labor market, indentifying potential sources for skill mismatches between the learning content provided in educational institutions and those relevant at work, which may impact negatively on the labor productivity of the educated workforce. Finally, country studies could refine the analysis by distinguishing the effects on returns to skills between multiple tradable and non-tradable sectors. 


\section{References}

Acemoglu, D. (2003). "Patterns of Skill Premia”. Review of Economic Studies 70, 199-230.

Acemoglu, D. and Autor, D. (2010). "Skills, Tasks and Technologies: Implications for Employment and Earnings". NBER Working Paper 16082.

Acosta, P. and Gasparini, L. (2007). "Capital Accumulation, Trade Liberalization, and Rising Wage Inequality: The Case of Argentina". Economic Development and Cultural Change 55.

Atolia, M. (2007). "Trade Liberalization and Rising Wage Inequality in Latin America: Reconciliation with HOS Theory”. Journal of International Economics 71, 467-494.

Attanasio, O., Goldberg, P. and Pavcnik, N. (2004). "Trade Reforms and Wage Inequality in Colombia". Journal of Development Economics 74, 331-366.

Autor, D., Katz, L. and Kearney, M. (2008). "Trends in US Wage Inequality: Revising the Revisionists". Review of Economics and Statistics 90, 300-323.

Baffes, J. and Haniotis, T. (2011). "Placing the 2006/08 Commodity Price Boom into Perspective". World Bank Policy Research Working Paper 5371.

Barro, R. and Lee, J (2010). “A New Data Set of Educational Attainment in the World, 1950-2010”, NBER Working Paper 15902.

Boeri, T., Garibaldi, P. and Ribeiro, M. (2011). "The Lighthouse Effect and Beyond." Review of Income and Wealth 57, S54-S78.

Bourguignon, F., Ferreira, F. and Lustig, N. (2005). The Microeconomics of Income Distribution Dynamics in East Asia and Latin America, World Bank and Oxford University Press, Washington, DC.

Brambilla, I., Dix-Carneiro, R., Lederman, D. and Porto, G. (2011). "Skills, Exports, and the Wages of Seven Million Latin American Workers". World Bank Economic Review, forthcoming.

Card, D. and Lemieux, T. (2001). "Can Falling Supply Explain the Rising Return to College for Young Men?” Quarterly Journal of Economics 116, 705-746.

Cruces, G., Garcia-Domenech, C. and Gasparini, L. (2011). "Inequality in Education Evidence for Latin America". Mimeo, CEDLAS-UNLP and UNU-WIDER.

De la Torre, A., T. Didier, C. Calderon, S. Pienknagura, T. Cordella, C. Aedo, and Walker, I. (2011). "LAC's Long-Term Growth: Made in China?", Biannual Report of the Office of the Chief Economist for Latin America of the World Bank.

DiNardo, J., Fortin, N. and Lemieux, T. (1996). "Labor Market Institutions and the Distribution of Wages, 1973-1992: A Semiparametric Approach”. Econometrica 64, 1001-1044.

Ferreira, F., Leite, P. and Wai-Poi, M. (2007). “Trade Liberalization, Employment Flows, and Wage Inequality in Brazil.” World Bank Policy Research Working Paper Series 4108.

Galiani, S. (2009). “Salarios y Educación en el Mercado Laboral Panameño”. Mimeo.

Galiani, S. and Porto, G. (2010). "Trends in Tariff Reforms and in the Structure of Wages." Review of Economics and Statistics 92, 482-494.

Galiani, S. and Sanguinetti, P. (2003). "The Impact of Trade Liberalization on Wage Inequality: Evidence from Argentina." Journal of Development Economics 72, 497-513.

Galiani, S., Heymann, D. and Magud, N. (2011). "Income Distribution, Factor Endowments, and Trade Revisited: The Role of Non-Tradable Goods". Available online at SSRN. 
Gallego, F. (2011). "Skill Premium in Chile: Studying Skill Upgrading in the South." World Development, forthcoming.

Gasparini, L. and Cruces, G. (2010). “A Distribution in Motion: The Case of Argentina.” In The New Dynamics of Income Inequality in Latin America. López-Calva, L. and Lustig, N. (eds.), Brookings Institution and UNDP, Washington DC.

Gasparini, L., Cruces, G. and Tornarolli, L. (2011). "Recent Trends in Income Inequality in Latin America". Economia 10, 147-201.

Gill, I. and C. Montenegro (2002). "Responding to Earnings Differentials in Chile." In I. Gill, D. Domeland and C. Montenegro (eds.), Crafting Labor Policy: Techniques and Lessons from Latin America, World Bank, Washington, DC.

Gindling, T. and Terrell, K. (2005). "The Effect of Minimum Wages on Actual Wages in Formal and Informal Sectors in Costa Rica." World Development 33, 1905-1921.

Goldberg, P. and Pavcnik, N. (2004), "Trade, Inequality, and Poverty: What Do We Know? Evidence from Recent Trade Liberalization Episodes in Developing Countries." NBER Working Paper N 10593.

Goldberg, P. and Pavcnik, N. (2007). "Distributional Effects of Globalization in Developing Countries." Journal of Economic Literature 45, 39-82.

Goldin, C. and Katz, L. (2007). "The Race Between Education and Technology: The Evolution of U.S. Educational Wage Differentials, 1890 to 2005”. NBER Working Paper No 12984.

Goldin, C. and Katz, L. (2008). The Race Between Education and Technology. Harvard University.

Harrison, A. and Hanson, G. (1999). "Who Gains from Trade Reform? Some Remaining Puzzles." Journal of Development Economics 59, 125-154,.

Katz, L. and Murphy, K. (1992). "Changes in Relative Wages, 1963-1987: Supply and Demand Factors". Quarterly Journal of Economics 107, 35-78.

Lemieux, T. (2006). "Increasing Residual Wage Inequality: Composition Effects, Noisy Data, or Rising Demand for Skill?" American Economic Review 96, 462-498.

Lindley, J and Machin, S. (2011) "Rising Wage Inequality and Postgraduate Education." IZA Discussion Paper 5981.

López-Calva, L. and Lustig, N. (2010). The New Dynamics of Income Inequality in Latin America. Brookings Institution and UNDP, Washington DC.

Manacorda, M., Sánchez-Páramo, C. and Schady, N. (2010). "Changes in Returns to Education in Latin America: The Role of Demand and Supply of Skills". Industrial and Labor Relations Review 63, 307-326.

Montes Rojas, G. (2006). "Skill Premia in Mexico: Demand and Supply factors." Applied Economics Letters 13, 917-924.

Tinbergen, J. (1975). Income Distribution: Analysis and Policies. North-Holland: Amsterdam.

World Bank (2011). Skills for the 21st Century in Latin America and the Caribbean. World Bank, Washington DC.

Yeaple, S. (2005). "A Simple Model of Firm Heterogeneity, International Trade and Wages." Journal of International Economics 65, 1-20. 


\section{Figures}

Figure 2.1

Percentage of the labor force by maximum educational level achieved, Latin America, 1950-2010

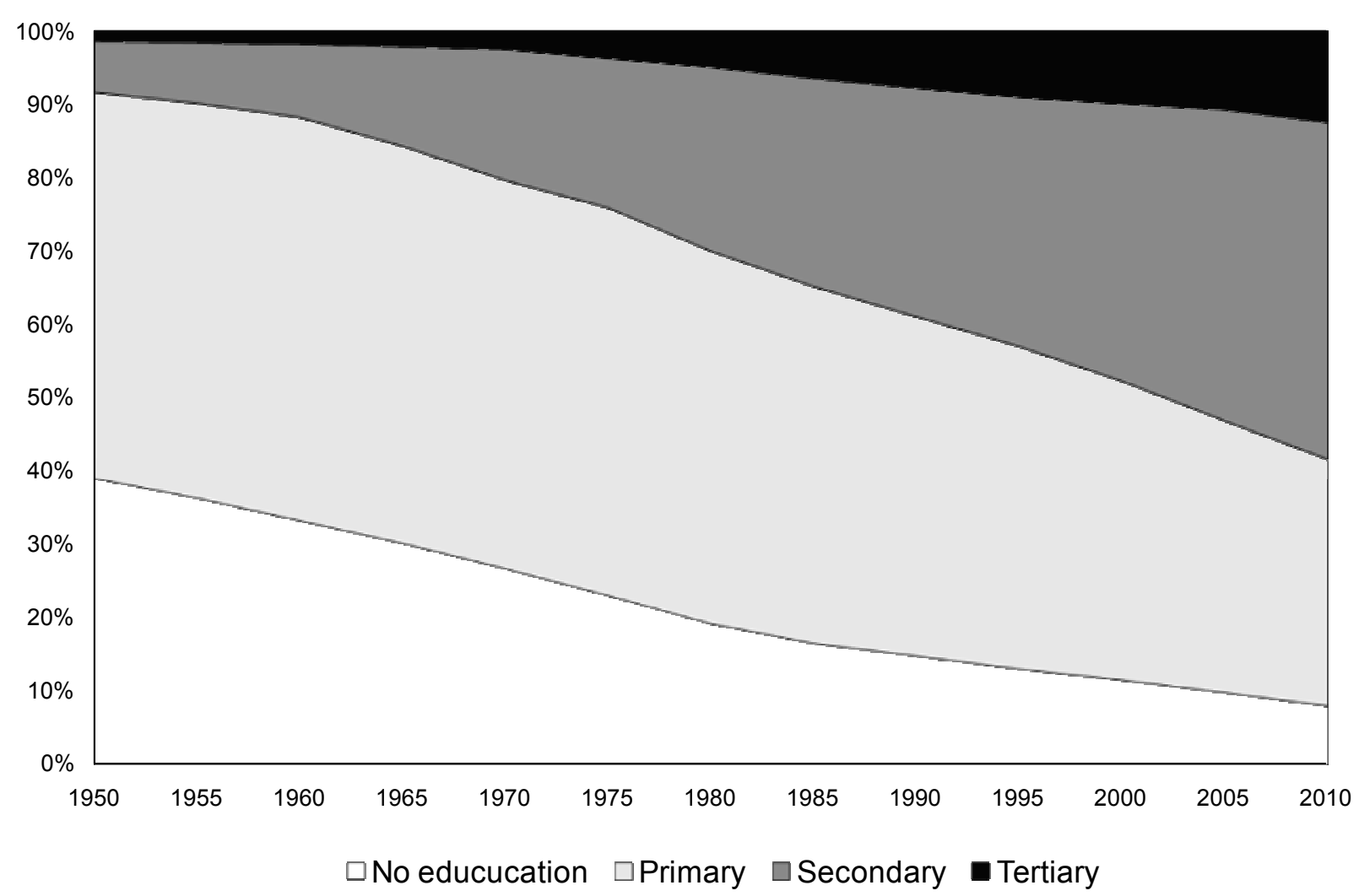

Source: Barro and Lee (2010).

Figure 2.2

Change in average years of education. 16 Latin American countries, c.1989-c.2009

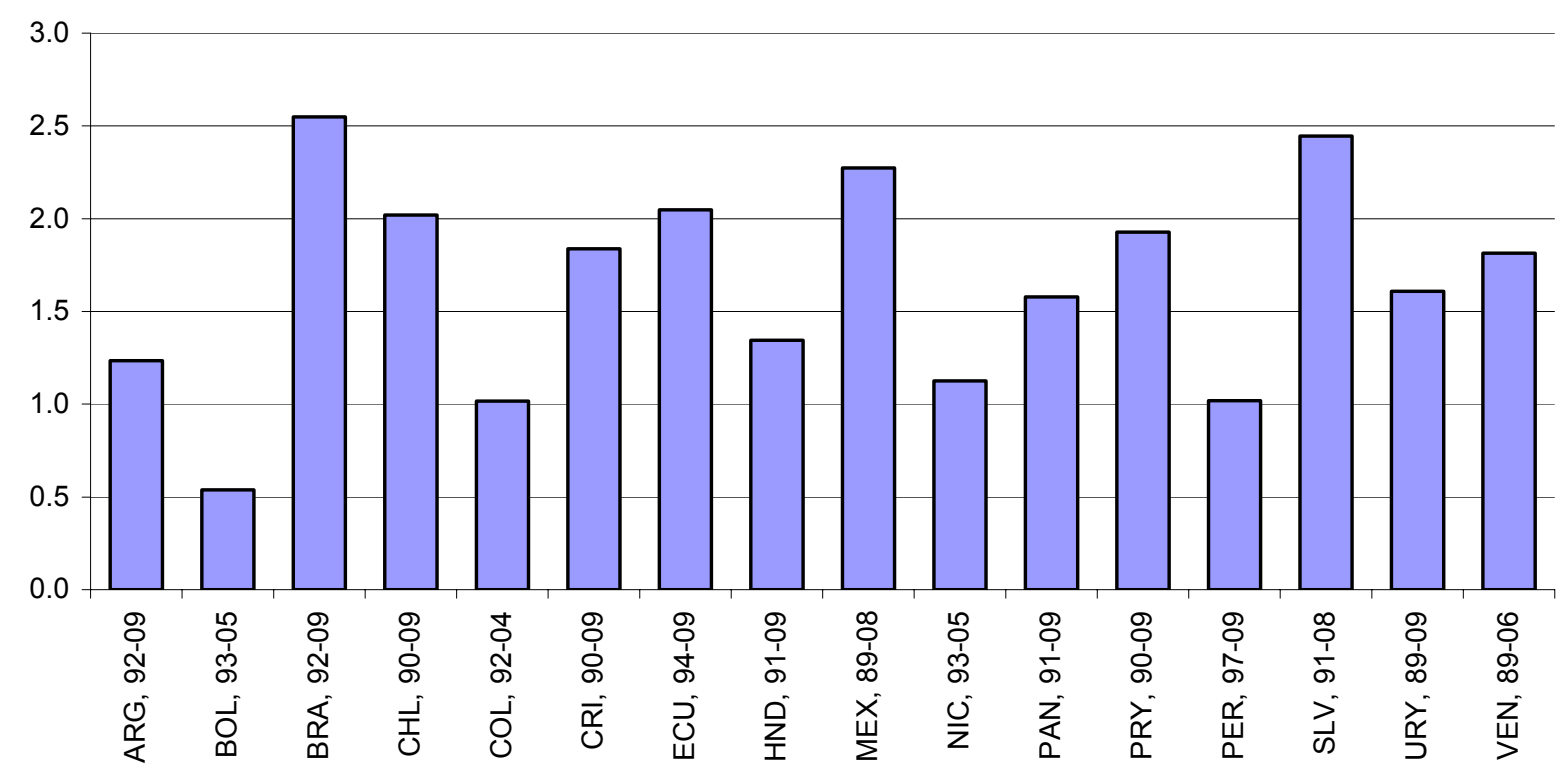

Source .Cruces et al (2011), based on SEDLAC (CEDLAS and World Bank). 
Figure 2.3

Distribution of the working age population by education level. 16 LA countries, c.1989-c.2009
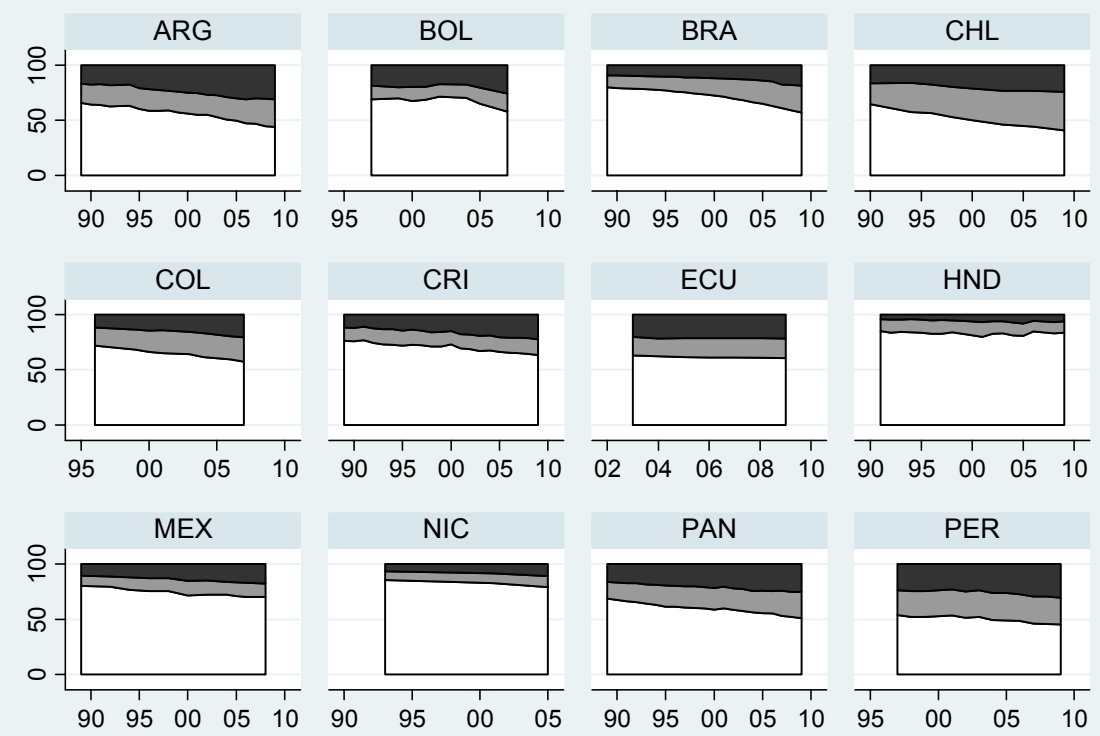

NIC

PAN

PER
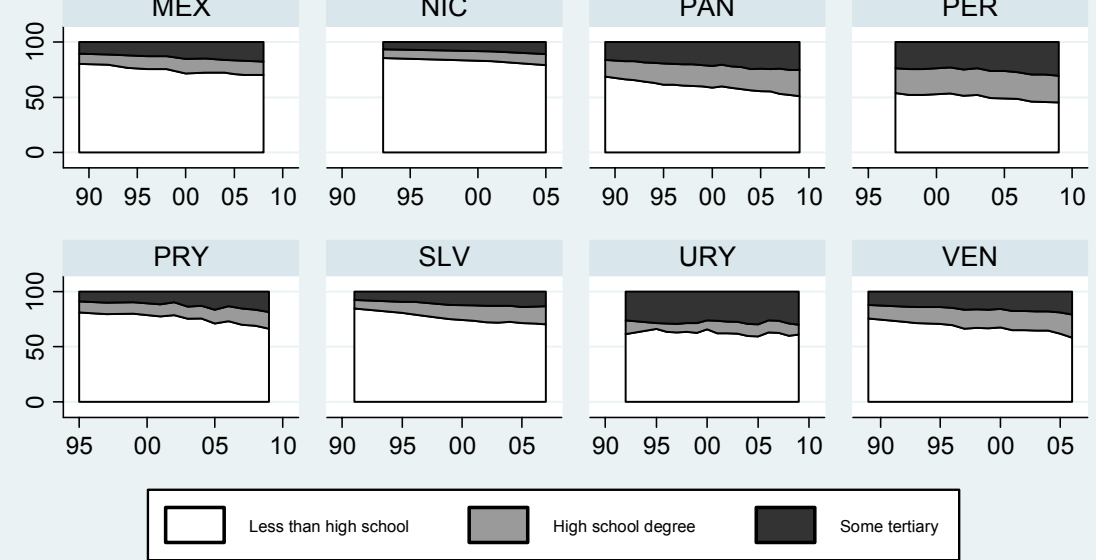

Source: Own computations based on SEDLAC (CEDLAS and World Bank).

Figure 2.4

Gini coefficient, poverty based on the 4USD international line and GDP. Average for Latin America, 1992-2009

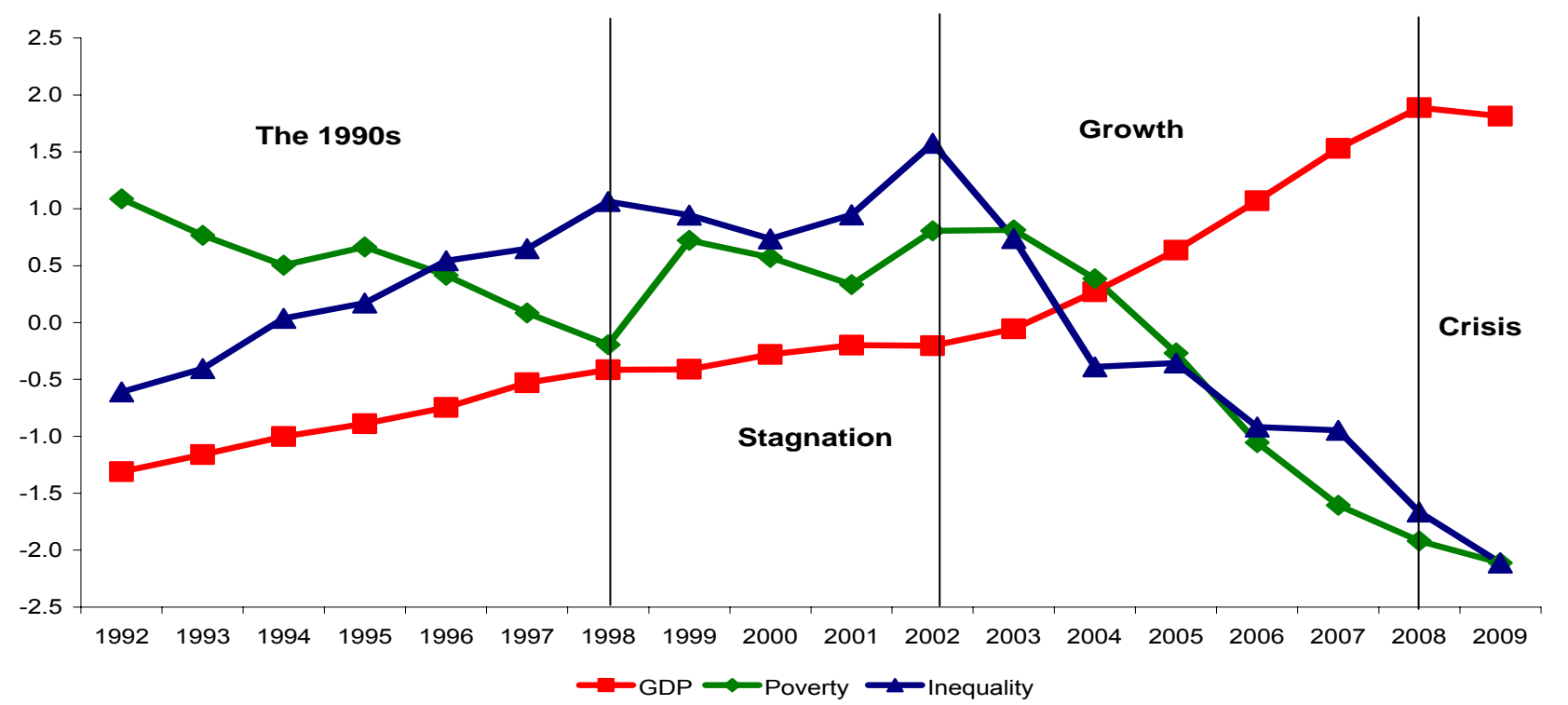

Source: Source: own computations based on SEDLAC (CEDLAS and World Bank) and World Development Indicators. 
Figure 3.1

Wage premiums and relative supplies over time, net of country effects.

16 LA countries, 1989-2009
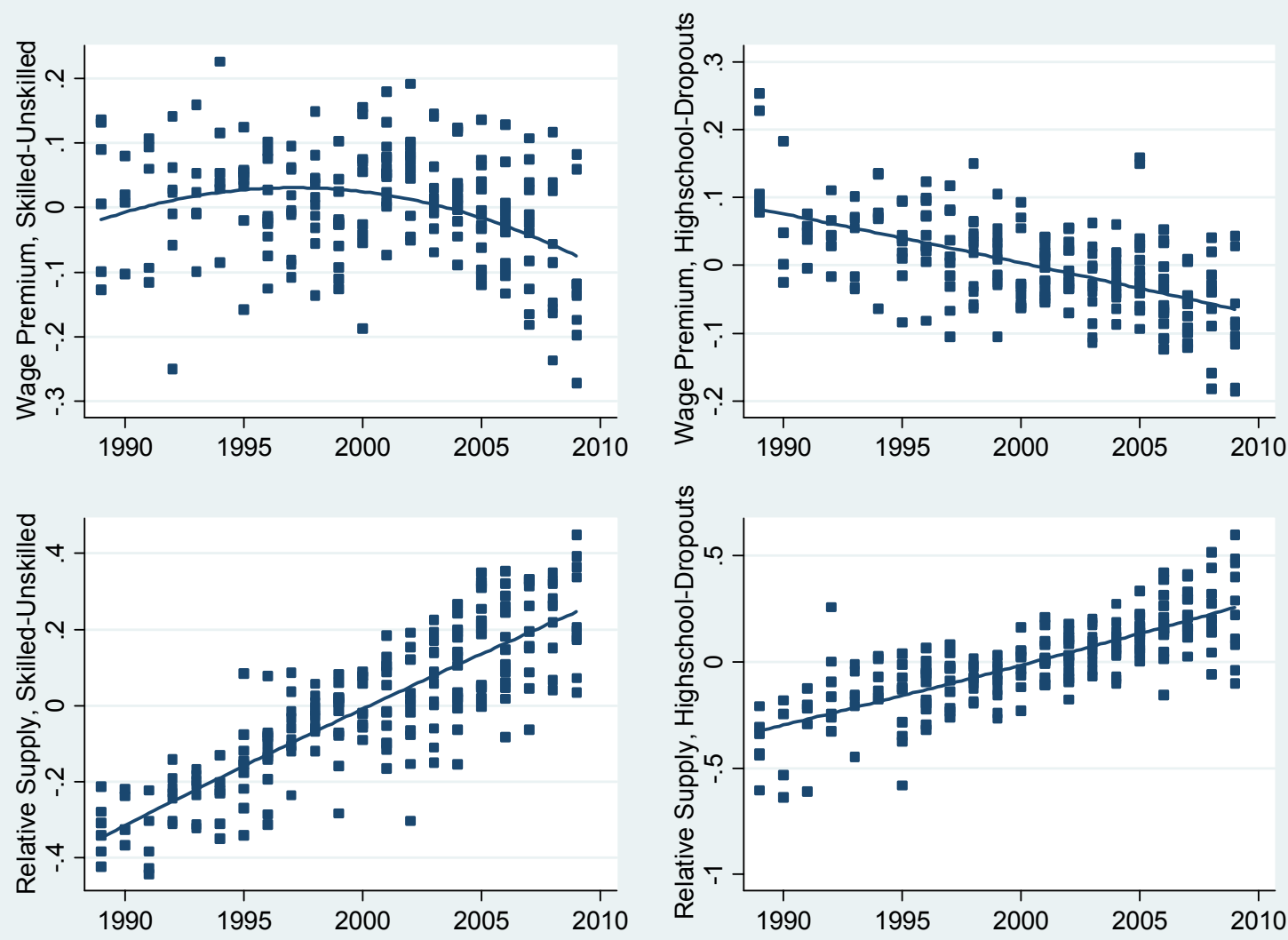

Source: own computations based on SEDLAC (CEDLAS and World Bank).

Figure 3.2

Relative demands over time (residual assuming $\sigma=3$ for both elasticities), net of country effects.

16 LA countries, 1989-2009
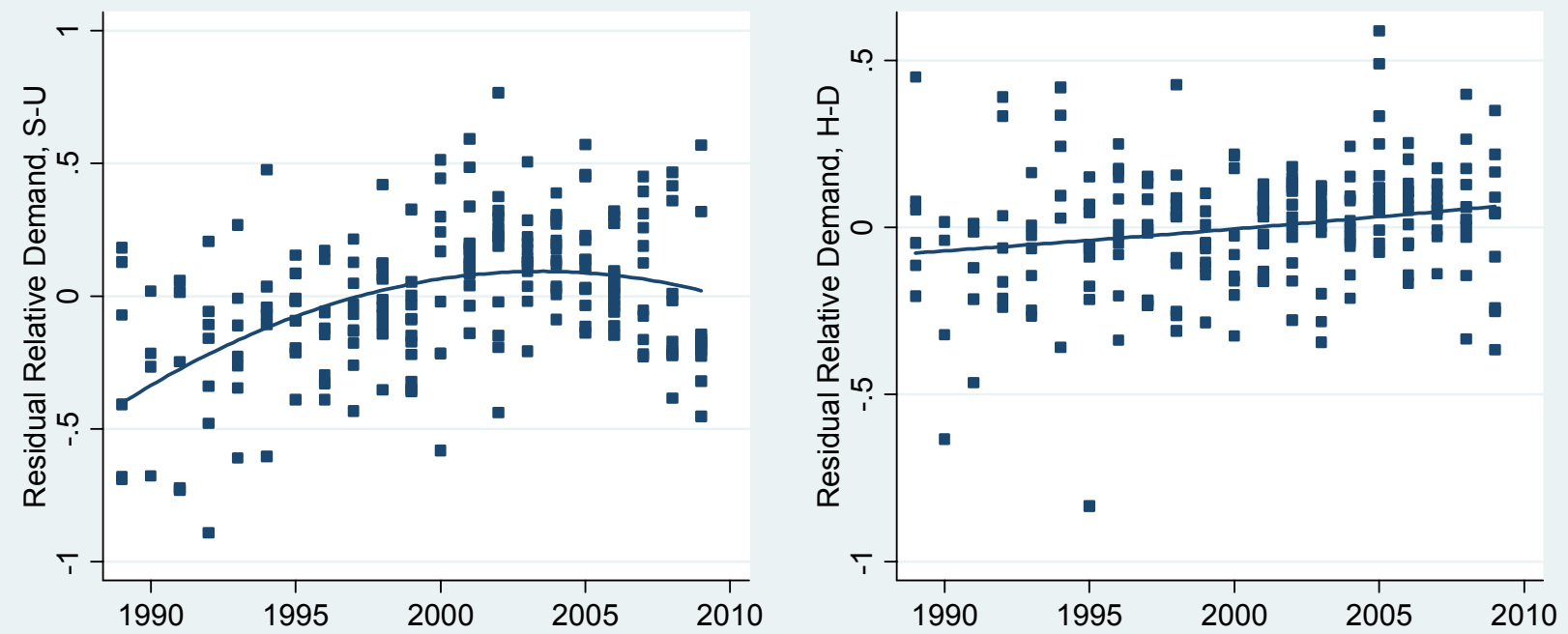

Source: own computations based on SEDLAC (CEDLAS and World Bank). 
Figure 3.3

Gini coefficient of household per capita income, skilled-unskilled and highschool-dropouts wage premiums over time, net of country effects. 16 LA countries, 1989-2009
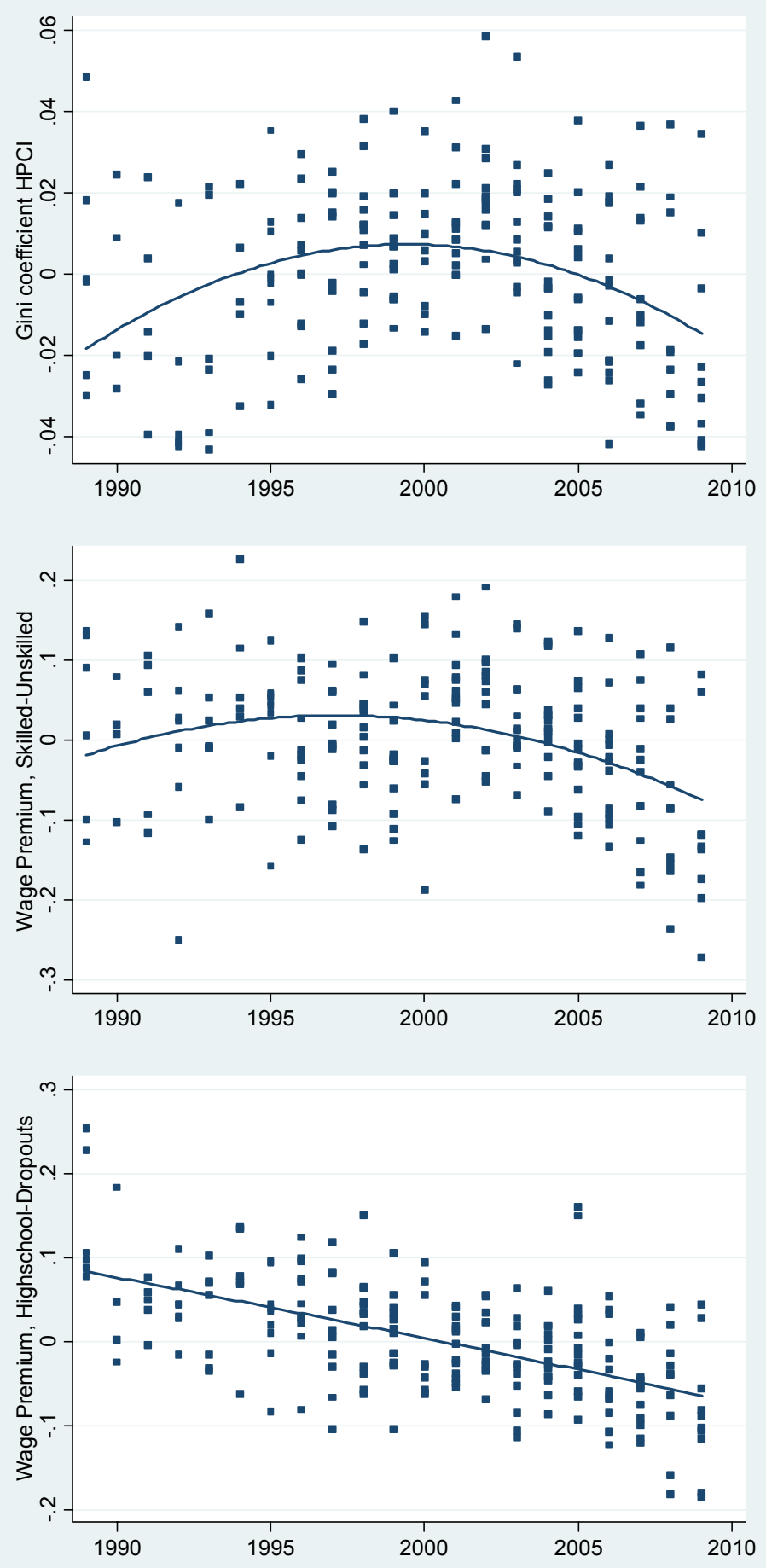

Source: own computations based on SEDLAC (CEDLAS and World Bank). 
Figure 3.4

Gini coefficient of household per capita income, skilled-unskilled and highschool-dropouts wage premiums. 16 LA countries, 1989-2009
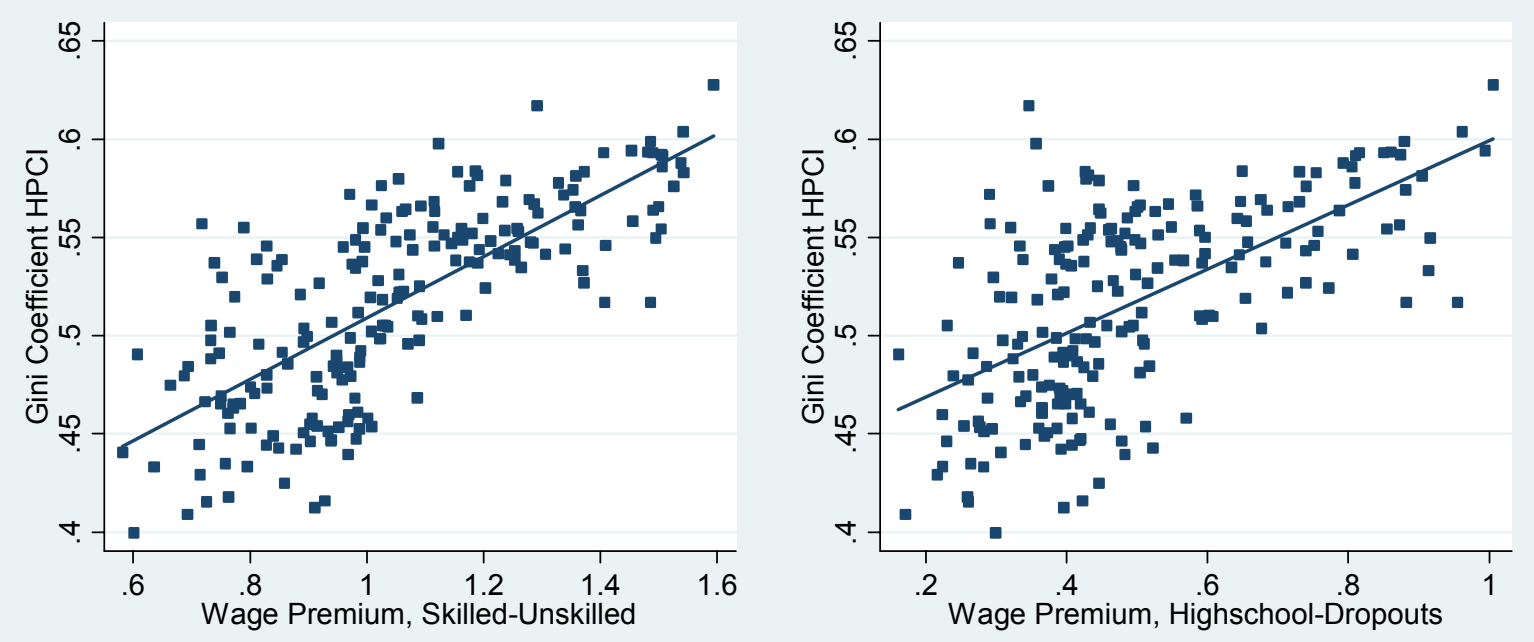

Source: own computations based on SEDLAC (CEDLAS and World Bank). 
Figure 5.1

Changes in sector shares of GDP, 1993-2009

a) Decade of 1990

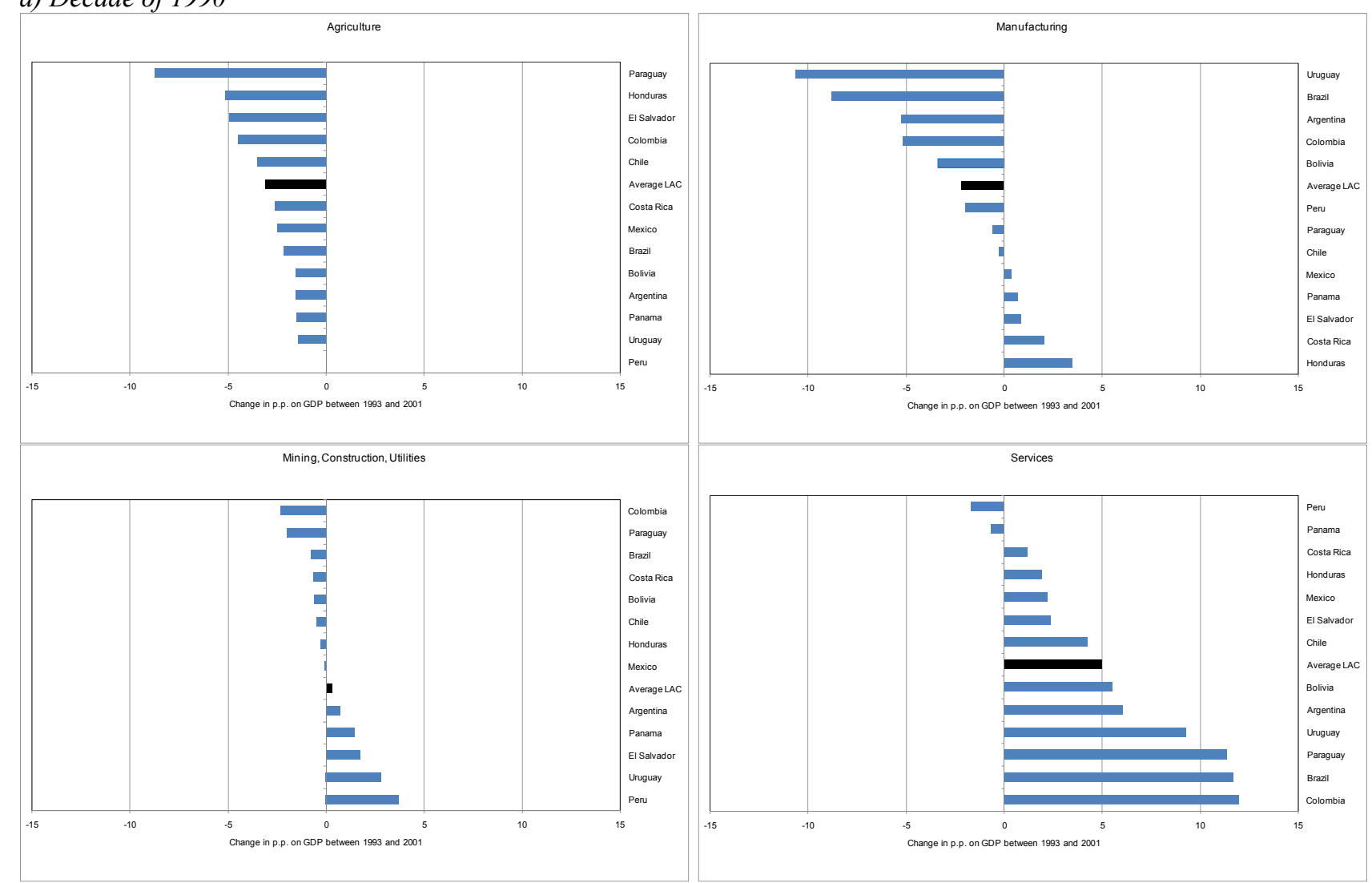

b) Decade of 2000
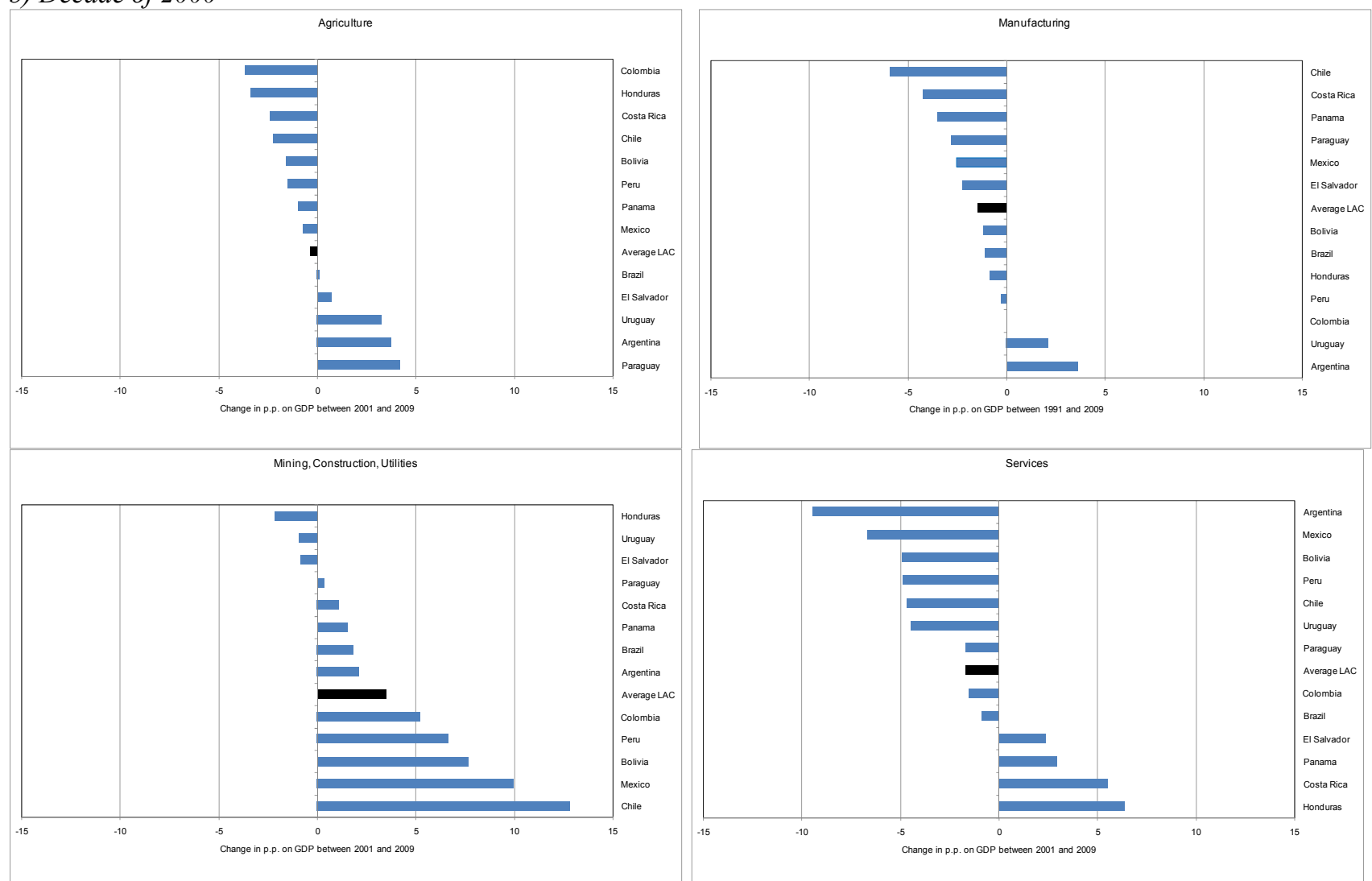

Source: Own calculations based on World Development Indicators. 
Figure 5.2

Change in employment of skilled workers, and between and within sector decomposition Annual percentage change, 1990s and 2000s

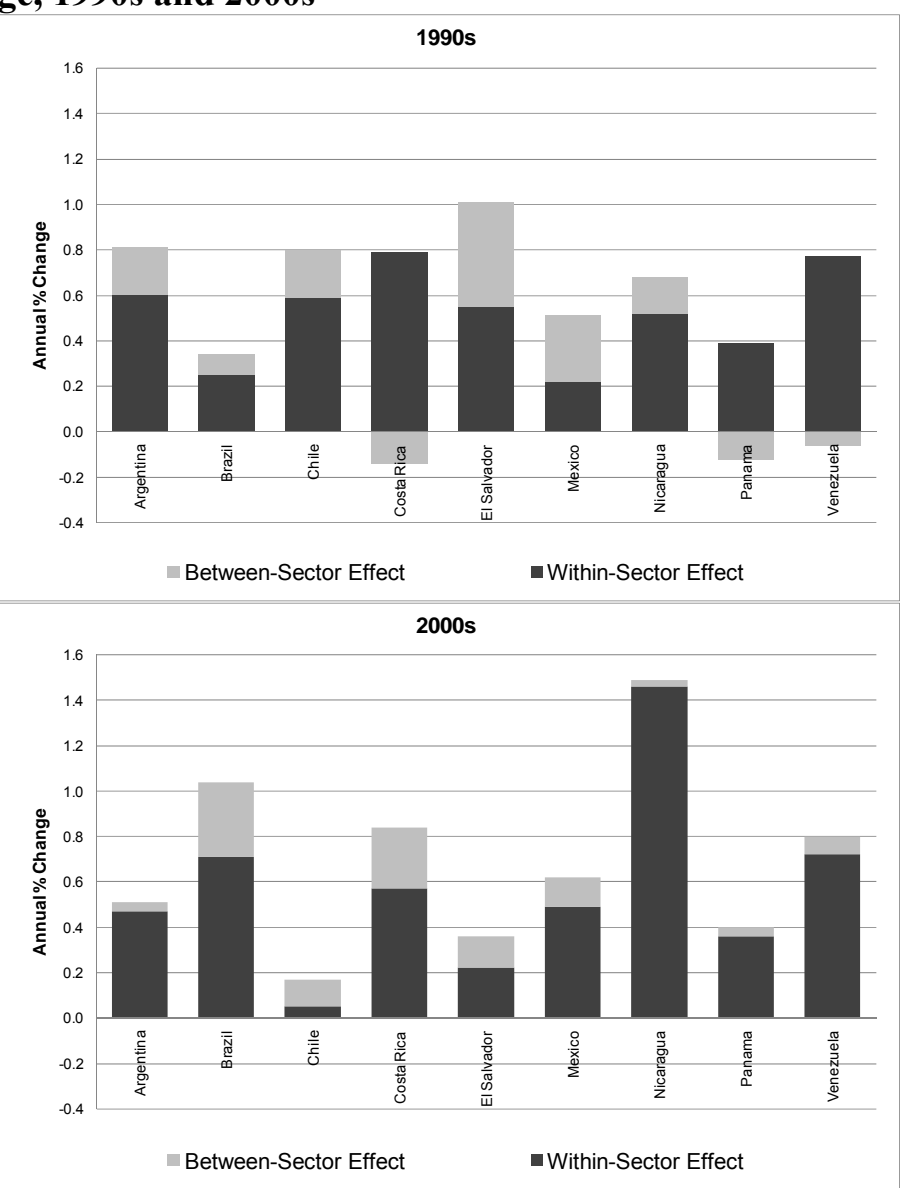

Source: own computations based on SEDLAC (CEDLAS and World Bank). 


\section{Tables}

Table 3.1

Changes in the wage premium and the relative supply and demand for skilled-unskilled workers assuming $\sigma_{\mathrm{SU}}=2$ and $\sigma_{\mathrm{SU}}=3$ (annual $\log$ changes multiplied by 100). Summary of results.

\begin{tabular}{|c|c|c|c|c|c|c|c|c|}
\hline & \multicolumn{2}{|c|}{ Wage premium } & \multicolumn{2}{|c|}{ Relative supply } & \multicolumn{2}{|c|}{$\begin{array}{c}\text { Relative demand } \\
\sigma s u=2\end{array}$} & \multicolumn{2}{|c|}{$\begin{array}{c}\text { Relative demand } \\
\sigma s u=3\end{array}$} \\
\hline & 1990s & $2000 s$ & 1990s & $2000 s$ & 1990s & $2000 s$ & 1990s & $2000 s$ \\
\hline Argentina & 3.5 & -2.4 & 4.6 & 2.4 & 11.5 & -2.3 & 15.0 & -4.7 \\
\hline Bolivia & 7.9 & -4.6 & -0.2 & 5.1 & 15.6 & -4.1 & 23.5 & -8.7 \\
\hline Brazil & -0.4 & -3.2 & 1.6 & 4.4 & 0.8 & -1.9 & 0.4 & -5.1 \\
\hline Chile & 0.5 & -1.9 & 3.1 & 1.1 & 4.1 & -2.7 & 4.6 & -4.7 \\
\hline Colombia & 2.5 & -2.0 & 6.4 & 6.0 & 11.5 & 2.1 & 14.0 & 0.1 \\
\hline Costa Rica & 0.4 & -0.2 & 4.0 & 3.4 & 4.9 & 3.0 & 5.3 & 2.8 \\
\hline Ecuador & & -3.2 & & 3.4 & & -3.0 & & -6.3 \\
\hline El Salvador & 1.7 & -0.1 & 5.5 & -0.3 & 8.9 & -0.4 & 10.6 & -0.5 \\
\hline Honduras & 0.0 & -1.9 & 2.6 & 2.3 & 2.6 & -1.4 & 2.6 & -3.3 \\
\hline Mexico & 1.8 & -2.8 & 3.6 & 2.2 & 7.2 & -3.5 & 9.0 & -6.3 \\
\hline Nicaragua & 3.5 & -6.9 & 4.6 & 6.6 & 11.6 & -7.2 & 15.0 & -14.1 \\
\hline Panama & 0.3 & -2.3 & 2.3 & 2.4 & 2.9 & -2.2 & 3.1 & -4.4 \\
\hline Paraguay & 0.8 & -5.6 & 5.3 & 6.1 & 6.9 & -5.2 & 7.6 & -10.8 \\
\hline Peru & 0.6 & -2.8 & 0.2 & 3.8 & 1.3 & -1.8 & 1.9 & -4.6 \\
\hline Uruguay & 2.3 & -0.9 & 2.9 & 1.1 & 7.4 & -0.6 & 9.6 & -1.4 \\
\hline Venezuela & 1.1 & -4.8 & 3.9 & 4.2 & 6.2 & -5.4 & 7.3 & -10.3 \\
\hline Mean & 1.8 & -2.8 & 3.4 & 3.4 & 6.9 & -2.3 & 8.6 & -5.1 \\
\hline
\end{tabular}

Source: own computations based on SEDLAC (CEDLAS and World Bank). 
Table 3.2

Changes in the wage premium and the relative supply and demand for unskilled workers (high schooldropouts) assuming $\sigma_{\mathrm{HD}}=2$ and $\sigma_{\mathrm{HD}}=3$ (annual log changes multiplied by 100). Summary of results

\begin{tabular}{|c|c|c|c|c|c|c|c|c|}
\hline & \multicolumn{2}{|c|}{ Wage premium } & \multicolumn{2}{|c|}{ Relative supply } & \multicolumn{2}{|c|}{$\begin{array}{c}\text { Relative demand } \\
\sigma \mathrm{hd}=2\end{array}$} & \multicolumn{2}{|c|}{$\begin{array}{c}\text { Relative demand } \\
\text { ohd }=3\end{array}$} \\
\hline & 1990s & $2000 s$ & $1990 \mathrm{~s}$ & $2000 s$ & 1990s & $2000 s$ & 1990s & $2000 s$ \\
\hline Argentina & 1.4 & 0.1 & 0.6 & 6.8 & 3.3 & 6.9 & 4.7 & 7.0 \\
\hline Bolivia & -2.7 & -0.8 & 2.6 & 5.2 & -2.8 & 3.6 & -5.5 & 2.8 \\
\hline Brazil & -1.7 & -2.1 & 4.5 & 7.3 & 1.0 & 3.1 & -0.8 & 0.9 \\
\hline Chile & 0.5 & -1.8 & 6.9 & 4.8 & 8.0 & 1.2 & 8.5 & -0.6 \\
\hline Colombia & -0.1 & -0.9 & 6.4 & 3.4 & 6.1 & 1.6 & 6.0 & 0.6 \\
\hline Costa Rica & -0.5 & 0.7 & 1.7 & 2.8 & 0.8 & 4.2 & 0.3 & 5.0 \\
\hline Ecuador & & -1.0 & & 2.8 & & 0.7 & & -0.3 \\
\hline El Salvador & -0.7 & -0.9 & 7.1 & 3.3 & 5.7 & 1.5 & 5.0 & 0.7 \\
\hline Honduras & -1.8 & 0.4 & 0.4 & -1.7 & -3.2 & -0.8 & -5.1 & -0.4 \\
\hline Mexico & -1.5 & -1.2 & 4.6 & -0.2 & 1.7 & -2.7 & 0.2 & -3.9 \\
\hline Nicaragua & -0.2 & -0.1 & 2.1 & 4.0 & 1.6 & 3.8 & 1.4 & 3.6 \\
\hline Panama & -1.2 & -0.7 & 2.9 & 5.0 & 0.5 & 3.5 & -0.8 & 2.8 \\
\hline Paraguay & -0.9 & -4.0 & 2.6 & 5.9 & 0.7 & -2.2 & -0.2 & -6.2 \\
\hline Peru & 1.0 & -2.1 & 1.7 & 1.5 & 3.6 & -2.7 & 4.6 & -4.8 \\
\hline Uruguay & -0.5 & 1.2 & -5.0 & -4.5 & -6.0 & -2.1 & -6.5 & -0.9 \\
\hline Venezuela & 0.0 & -2.7 & 2.9 & 7.6 & 3.0 & 2.3 & 3.0 & -0.4 \\
\hline Mean & -0.6 & -1.0 & 2.8 & 3.4 & 1.6 & 1.4 & 1.0 & 0.4 \\
\hline
\end{tabular}

Source: own computations based on SEDLAC (CEDLAS and World Bank). 
Table 4.1

Correlates of the skilled-unskilled wage premium. 16 LA countries, 1989-2009

\begin{tabular}{|c|c|c|c|c|c|c|c|c|c|c|}
\hline & \multirow[b]{2}{*}{$\begin{array}{c}\text { Simple } \\
\text { OLS } \\
(1)\end{array}$} & \multirow{2}{*}{$\begin{array}{c}\text { Country } \\
\text { fixed } \\
\text { effects } \\
(2) \\
\end{array}$} & \multicolumn{8}{|c|}{ Country and year fixed effects } \\
\hline & & & $(3)$ & $(4)$ & $(5)$ & $(6)$ & $\begin{array}{c}\text { Controls } \\
(7)\end{array}$ & $\begin{array}{l}\text { Controls, } \\
\text { min w. } \\
(8)\end{array}$ & $\begin{array}{c}\text { Excl. VEN } \\
\text { CHL } \\
(9) \\
\end{array}$ & $\begin{array}{c}\text { Long } \\
\text { series } \\
(10) \\
\end{array}$ \\
\hline \multirow[t]{2}{*}{ Relative supply } & -0.2195 & -0.1435 & -0.203 & -0.1671 & -0.1646 & -0.1729 & -0.1474 & -0.2689 & -0.1608 & -0.2062 \\
\hline & {$[0.0260]^{\star * *}$} & {$[0.0619]^{\star *}$} & [0.1849] & {$[0.1616]$} & [0.1573] & {$[0.1596]$} & {$[0.1556]$} & {$[0.1337]^{*}$} & {$[0.1564]$} & [0.2252] \\
\hline \multirow{2}{*}{$\begin{array}{l}\text { Log Net Barter Terms } \\
\text { of Trade }\end{array}$} & & & & -0.1824 & -0.1911 & -0.1858 & -0.1751 & -0.1633 & -0.2525 & -0.2086 \\
\hline & & & & {$[0.0544]^{\star * *}$} & {$[0.0533]^{* * *}$} & {$[0.0492]^{\star * *}$} & {$[0.0580]^{* * *}$} & {$[0.0539]^{* * *}$} & {$[0.1088]^{\star *}$} & {$[0.0698]^{* *}$} \\
\hline \multirow{2}{*}{$\begin{array}{l}\text { Aggregate } \\
\text { unemployment rate }\end{array}$} & & & & & 0.6656 & & 1.0884 & 0.5989 & 0.7705 & 1.1363 \\
\hline & & & & & {$[0.5213]$} & & {$[0.5434]^{*}$} & {$[0.5388]$} & {$[0.4837]$} & {$[0.4445]^{* *}$} \\
\hline \multirow{2}{*}{$\begin{array}{l}\text { Unskilled } \\
\text { unemployment rate }\end{array}$} & & & & & & 0.8390 & & & & \\
\hline & & & & & & {$[0.4748]^{*}$} & & & & \\
\hline \multirow{2}{*}{$\begin{array}{l}\text { Skilled unmeployment } \\
\text { rate }\end{array}$} & & & & & & -0.2548 & & & & \\
\hline & & & & & & [0.5658] & & & & \\
\hline \multirow{2}{*}{$\begin{array}{l}\text { Log minimum wage } \\
\text { index }(1995+)\end{array}$} & & & & & & & & -0.0396 & & \\
\hline & & & & & & & & {$[0.0654]$} & & \\
\hline \multirow{2}{*}{ Constant } & 0.9062 & 0.9551 & 0.8694 & 1.7065 & 1.7162 & 1.6855 & -0.6757 & 1.627 & 1.9858 & 1.7083 \\
\hline & {$[0.0215]^{\star \star *}$} & {$[0.0398]^{\star \star *}$} & {$[0.1892]^{\star * *}$} & {$[0.1939]^{\star \star *}$} & {$[0.1816]^{* * *}$} & {$[0.1623]^{\star * *}$} & [1.5420] & [1.6355] & {$[0.4587]^{\star * *}$} & {$[0.2541]^{* * *}$} \\
\hline Observations & 209 & 209 & 209 & 209 & 209 & 209 & 209 & 178 & 186 & 141 \\
\hline R-squared & 0.03 & 0.37 & 0.48 & 0.49 & 0.50 & 0.50 & 0.51 & 0.44 & 0.52 & 0.58 \\
\hline Year effects & No & No & Yes & Yes & Yes & Yes & Yes & Yes & Yes & Yes \\
\hline Country effects & No & Yes & Yes & Yes & Yes & Yes & Yes & Yes & Yes & Yes \\
\hline Additional controls & No & No & No & No & No & No & Yes & Yes & No & No \\
\hline
\end{tabular}

Source: own computations based on SEDLAC (CEDLAS and World Bank) and WDI (World Bank).

Notes: Robust standard errors in brackets, clustered at the country level for models 3-10. * significant at 10\%; ** significant at 5\%; *** significant at $1 \%$. The additional control variables include the log of GDP per capita, the log of the real exchange rate against the US Dollar (both from WDI), and the log of a tariff index. Column 8 includes the $\log$ of a minimum wage index compiled by ILO (available only for 1995-2009). The regressions in column 10 only include the nine countries for which there is a relatively long, continuous and homogeneous data source: Argentina, Brazil, Chile, Costa Rica, Mexico, Panama, El Salvador, Uruguay and Venezuela. 
Table 4.2

Correlates of the highschool-dropout wage premium. 16 LA countries, 1989-2009

\begin{tabular}{|c|c|c|c|c|c|c|c|c|c|c|}
\hline & \multirow[b]{2}{*}{$\begin{array}{c}\text { Simple } \\
\text { OLS } \\
(1)\end{array}$} & \multirow{2}{*}{$\begin{array}{c}\text { Country } \\
\text { fixed } \\
\text { effects } \\
(2) \\
\end{array}$} & \multicolumn{8}{|c|}{ Country and year fixed effects } \\
\hline & & & $(3)$ & $(4)$ & $(5)$ & $(6)$ & $\begin{array}{c}\text { Controls } \\
(7) \\
\end{array}$ & $\begin{array}{l}\text { Controls, } \\
\text { min w. } \\
(8)\end{array}$ & $\begin{array}{c}\text { Excl. VEN } \\
\text { CHL } \\
(9) \\
\end{array}$ & $\begin{array}{c}\text { Long } \\
\text { series } \\
(10) \\
\end{array}$ \\
\hline \multirow[t]{2}{*}{ Relative supply } & -0.0759 & -0.2048 & -0.1198 & -0.1099 & -0.109 & -0.1113 & -0.1295 & -0.1496 & -0.1175 & -0.1037 \\
\hline & {$[0.0294]^{\star *}$} & {$[0.0419]^{\star * *}$} & {$[0.0561]^{\star *}$} & {$[0.0603]^{*}$} & {$[0.0618]^{*}$} & {$[0.0611]^{*}$} & {$[0.0614]^{*}$} & {$[0.0662]^{* *}$} & {$[0.0659]^{*}$} & {$[0.0938]$} \\
\hline \multirow{2}{*}{$\begin{array}{l}\text { Log Net Barter Terms } \\
\text { of Trade }\end{array}$} & & & & -0.0594 & -0.0628 & -0.0583 & -0.0533 & -0.0474 & -0.1235 & -0.0653 \\
\hline & & & & [0.0479] & {$[0.0474]$} & {$[0.0456]$} & {$[0.0433]$} & {$[0.0471]$} & {$[0.0610]^{*}$} & {$[0.0565]$} \\
\hline \multirow{2}{*}{$\begin{array}{l}\text { Aggregate } \\
\text { unemployment rate }\end{array}$} & & & & & 0.2623 & & 0.3255 & 0.6925 & 0.1334 & 0.5055 \\
\hline & & & & & {$[0.2886]$} & & {$[0.2976]$} & [0.4263] & [0.3073] & {$[0.3068]$} \\
\hline \multirow{2}{*}{$\begin{array}{l}\text { Dropout } \\
\text { unemployment rate }\end{array}$} & & & & & & 0.6113 & & & & \\
\hline & & & & & & [0.3732] & & & & \\
\hline \multirow{2}{*}{$\begin{array}{l}\text { High school } \\
\text { unmeployment rate }\end{array}$} & & & & & & -0.4127 & & & & \\
\hline & & & & & & {$[0.5183]$} & & & & \\
\hline \multirow{2}{*}{$\begin{array}{l}\text { Log minimum wage } \\
\text { index }(1995+)\end{array}$} & & & & & & & & 0.0304 & & \\
\hline & & & & & & & & {$[0.0432]$} & & \\
\hline \multirow{2}{*}{ Constant } & 0.4214 & 0.2975 & 0.4813 & 0.7559 & 0.7601 & 0.7377 & -0.2807 & -1.0093 & 1.0445 & 0.7386 \\
\hline & {$[0.0264]^{* * *}$} & {$[0.0402]^{\star \star *}$} & {$[0.0739]^{\star * *}$} & {$[0.2620]^{\star *}$} & {$[0.2569]^{* * *}$} & {$[0.2484]^{* * *}$} & [1.0656] & [1.2676] & {$[0.3181]^{\star * *}$} & {$[0.3106]^{* *}$} \\
\hline Observations & 209 & 209 & 209 & 209 & 209 & 209 & 209 & 178 & 186 & 141 \\
\hline R-squared & 0.03 & 0.37 & 0.48 & 0.49 & 0.50 & 0.50 & 0.51 & 0.44 & 0.52 & 0.58 \\
\hline Year effects & No & No & Yes & Yes & Yes & Yes & Yes & Yes & Yes & Yes \\
\hline Country effects & No & Yes & Yes & Yes & Yes & Yes & Yes & Yes & Yes & Yes \\
\hline Additional controls & No & No & No & No & No & No & Yes & Yes & No & No \\
\hline
\end{tabular}

Source: own computations based on SEDLAC (CEDLAS and World Bank) and WDI (World Bank).

Notes: Robust standard errors in brackets, clustered at the country level for models 3-10. * significant at 10\%; ** significant at 5\%; *** significant at $1 \%$. The additional control variables include the log of GDP per capita, the log of the real exchange rate against the US Dollar (both from WDI), and the log of a tariff index. Column 8 includes the $\log$ of a minimum wage index compiled by ILO (available only for 1995-2009). The regressions in column 10 only include the nine countries for which there is a relatively long, continuous and homogeneous data source: Argentina, Brazil, Chile, Costa Rica, Mexico, Panama, El Salvador, Uruguay and Venezuela. 
Table 5.1

Changes in employment by skill level and between and within sector decompositions.

Annual Percentage Change, 1990s and 2000s. Summary of results

Overall change

\begin{tabular}{|c|c|c|c|c|c|c|}
\hline & \multicolumn{3}{|c|}{ 1990s } & \multicolumn{3}{|c|}{$2000 \mathrm{~s}$} \\
\hline & skilled & high school & dropouts & skilled & high school & dropouts \\
\hline$\overline{\text { Argentina }}$ & 0.81 & 0.05 & -0.86 & 0.51 & 0.62 & -1.13 \\
\hline Brazil & 0.34 & 0.54 & -0.88 & 1.04 & 0.68 & -1.71 \\
\hline Chile & 0.80 & 0.62 & -1.42 & 0.17 & 0.50 & -0.66 \\
\hline Costa Rica & 0.65 & -0.17 & -0.48 & 0.84 & 0.08 & -0.92 \\
\hline El Salvador & 1.01 & 0.67 & -1.68 & 0.36 & 0.45 & -0.82 \\
\hline Mexico & 0.51 & 0.46 & -0.97 & 0.62 & -0.15 & -0.47 \\
\hline Nicaragua & 0.68 & -0.05 & -0.63 & 1.49 & 0.16 & -1.65 \\
\hline Panama & 0.27 & -0.08 & -0.19 & 0.40 & 0.53 & -0.93 \\
\hline Venezuela & 0.71 & 0.27 & -0.98 & 0.80 & 0.66 & -1.46 \\
\hline Mean & 0.64 & 0.26 & -0.90 & 0.69 & 0.39 & -1.08 \\
\hline \multicolumn{7}{|c|}{ Between effect } \\
\hline & \multicolumn{3}{|c|}{$1990 \mathrm{~s}$} & \multicolumn{3}{|c|}{$2000 s$} \\
\hline & skilled & high school & dropouts & skilled & high school & dropouts \\
\hline Argentina & 0.21 & 0.02 & -0.23 & 0.04 & -0.02 & -0.02 \\
\hline Brazil & 0.09 & 0.03 & -0.12 & 0.33 & 0.06 & -0.39 \\
\hline Chile & 0.21 & 0.05 & -0.26 & 0.12 & -0.03 & -0.09 \\
\hline Costa Rica & -0.14 & -0.01 & 0.14 & 0.27 & 0.02 & -0.30 \\
\hline EI Salvador & 0.46 & 0.21 & -0.67 & 0.14 & 0.05 & -0.19 \\
\hline Mexico & 0.29 & 0.13 & -0.42 & 0.13 & 0.04 & -0.17 \\
\hline Nicaragua & 0.16 & 0.07 & -0.24 & 0.03 & -0.01 & -0.02 \\
\hline Panama & -0.12 & -0.05 & 0.17 & 0.04 & 0.01 & -0.06 \\
\hline Venezuela & -0.06 & 0.05 & 0.01 & 0.08 & -0.02 & -0.06 \\
\hline Mean & 0.12 & 0.06 & -0.18 & 0.13 & 0.01 & -0.14 \\
\hline \multicolumn{7}{|l|}{ Within effect } \\
\hline & \multicolumn{3}{|c|}{ 1990s } & \multicolumn{3}{|c|}{$2000 s$} \\
\hline & skilled & high school & dropouts & skilled & high school & dropouts \\
\hline Argentina & 0.60 & 0.03 & -0.63 & 0.47 & 0.64 & -1.11 \\
\hline Brazil & 0.24 & 0.51 & -0.75 & 0.70 & 0.62 & -1.32 \\
\hline Chile & 0.59 & 0.58 & -1.17 & 0.04 & 0.53 & -0.57 \\
\hline Costa Rica & 0.78 & -0.16 & -0.62 & 0.57 & 0.05 & -0.62 \\
\hline EI Salvador & 0.55 & 0.46 & -1.01 & 0.22 & 0.41 & -0.63 \\
\hline Mexico & 0.22 & 0.33 & -0.55 & 0.49 & -0.19 & -0.30 \\
\hline Nicaragua & 0.51 & -0.12 & -0.39 & 1.46 & 0.17 & -1.63 \\
\hline Panama & 0.39 & -0.02 & -0.37 & 0.36 & 0.52 & -0.87 \\
\hline Venezuela & 0.77 & 0.22 & -0.98 & 0.72 & 0.68 & -1.41 \\
\hline Mean & 0.52 & 0.20 & -0.72 & 0.56 & 0.38 & -0.94 \\
\hline
\end{tabular}

Source: own computations based on SEDLAC (CEDLAS and World Bank). 


\section{A. Methodological Appendix}

\section{A1.Basic Katz and Murphy (1992) supply and demand framework with two inputs}

The methodology in this document follows the literature initiated by Katz and Murphy's (1992) seminal work and subsequent contributions. The basic framework assumes a CES production function with two factors:

$$
Q_{t}=A_{t}\left[\lambda_{t} S_{t}^{\rho}+\left(1-\lambda_{t}\right) U_{t}^{\rho}\right]^{\frac{1}{\rho}}
$$

where $Q$ is output; $A$ is total factor productivity; $\lambda$ and $\rho$ are technology parameters; and $S$ and $U$ are the two factors that represent units of skilled and unskilled labor, respectively.

Under perfect competition, the wage skill premium $\left(w_{s} / w_{u}\right)$ in year $t$ satisfies the following relationship:

$$
\log \left(\frac{w_{S}(t)}{w_{U}(t)}\right)=\frac{1}{\sigma}\left[D(t)-\log \left(\frac{S(t)}{U(t)}\right)\right]
$$

where $\sigma=(1-\rho)^{-1}$ is the elasticity of substitution between the two types of labor, and $D(t)$ is the relative demand for these two factors measured in log quantity units. Under the assumption that the economy operates on the demand curve given by equation (A1), a given value of the elasticity of substitution between factors implies a time series of demand shifts:

$$
D(t)=\sigma \log \left(\frac{w_{S}(t)}{w_{U}(t)}\right)+\log \left(\frac{S(t)}{U(t)}\right)
$$

The greater the elasticity of substitution between the two factors, the greater must be the fluctuations in $D(t)$ to explain any given time series of relative prices for a given time series of observed relative quantities. The two logged terms on the right hand side of equation (A3) can be constructed from observational data. Following the literature initiated by Katz and Murphy (1992), equation (A3) can be used to impute $D(t)$ (which is not observable) conditional on a range of values for $\sigma$.

An estimate of the elasticity of substitution $\sigma$ is needed to implement (A3). Most of the literature gets that estimation from the inverse of the coefficient of the relative supply of skilled labor in a wage gap regression controlling by proxies of the relative demand - usually a time trend, linear or of higher order. The mean value of $\sigma$ in our regression analysis indicates values fluctuating around 4, while Manacorda et al. (2010) find values around 3 for Latin America. Goldin and Katz (2007), in the context of the United States, report values of around 1.6. The tables in the document will show results, alternatively, for $\sigma$ equal to 3 and 4 .

\section{A2. Augmented model with three levels of skills}

The basic Katz and Murphy (1992) framework for analyzing the impact of supply and demand factors on the wage skill premium relies on two broad aggregates of labor - skilled and unskilled. 
However, the evidence for Latin America indicates that the group of workers with secondary education was by far the one that increased the most since at least the 1970s (Manacorda et al., 2010; Cruces et al., 2011). This suggests that the analysis of returns to skills in the region would be enriched by studying the evolution of premiums, supply and demand factor within the group of the unskilled. Following Goldin and Katz (2007), the basic CES production function (A1) can be augmented to accommodate three levels of skills, by partitioning the group of the unskilled. Goldin and Katz (2007) propose a specification which maintains the previous CES setup, but considers $U$ to be a composite factor - a CES sub-aggregate of the form:

$$
U_{t}=\left[\theta_{t} H_{t}^{\eta}+\left(1-\theta_{t}\right) D_{t}^{\eta}\right]^{\frac{1}{\eta}}
$$

where $\theta$ and $\eta$ are additional technology parameters, and $H$ and $D$ are units of high school graduate labor and labor with less than a high school degree (referred to as high school dropouts), respectively. Within this extended framework, relative wages depend on two demand shifters $\left(\lambda_{t}\right.$ and $\theta_{t}$ ), on the relative supply of the more and less educated groups, and on the two relevant elasticities of substitution $\sigma_{S U}=(1-\rho)^{-1}$ and $\sigma_{H D}=(1-\eta)^{-1}$ :

$$
\begin{aligned}
& \log \left(\frac{w_{S_{t}}}{w_{U_{t}}}\right)=\log \left(\frac{\lambda_{t}}{1-\lambda_{t}}\right)-\frac{1}{\sigma_{S U}} \log \left(\frac{S_{t}}{U_{t}}\right) \\
& \log \left(\frac{w_{H_{t}}}{w_{D_{t}}}\right)=\log \left(\frac{\theta_{t}}{1-\theta_{t}}\right)-\frac{1}{\sigma_{H D}} \log \left(\frac{H_{t}}{D_{t}}\right)
\end{aligned}
$$

As in the previous section, it is possible to obtain correlates of these two wage skill premiums (left hand side terms) and of their relative supplies (last terms on the right hand side). The skilledunskilled wage premium captures the traditional Katz and Murphy (1992) skill premium, while the second term represents the high school premium - the difference in wages within the two groups that constitute the unskilled aggregate. Manacorda et al. (2010) analyze trends in wage premia using a Card-Lémieux analysis for Argentina, Brazil, Chile, Colombia and México for the 1980s and 1990s, using a more elaborate model to include these three skill groups as production inputs. As argued by Galiani (2009) in his analysis of Panama, the model presented here is more parsimonious, and sufficient to study a higher degree of disaggregation within the labor force without introducing unnecessary complications in the estimation phase. 


\section{B. Appendix: Empirical calculations of wage premia}

\section{B1.The SEDLAC dataset and sample}

The evidence is drawn from the analysis of microdata from a large set of household surveys that are part of the Socioeconomic Database for Latin America and the Caribbean (SEDLAC), jointly developed by CEDLAS at the Universidad Nacional de La Plata (Argentina) and the World Bank's LAC poverty group (LCSPP). This database contains information on more than 200 official household surveys in the region (see sedlac.econo.unlp.edu.ar). All variables in SEDLAC are constructed using consistent criteria across countries and years, subject to the constraint of the survey questionnaires, and identical programming routines.

The document covers a set of 16 Latin American economies: Argentina, Brazil, Bolivia, Chile, Colombia, Costa Rica, Ecuador, El Salvador, Honduras, Mexico, Nicaragua, Panama, Paraguay, Peru, Uruguay and Venezuela. Only Guatemala is missing among the continental Latin American countries. The sample represents 97.5 percent of the total Latin American population.

In this study, the sample for each country includes all individuals aged 26-56 that have fully coherent answers about income and education in the corresponding household surveys. For the wage premia, and following Manacorda et.al (2010), the analysis attempts to control for the secular increase in female labor force participation by computing premiums from a sample of male workers only.

\section{B2.Construction of wage premia}

Skilled workers are defined as those with some college education (complete or incomplete), and the unskilled as those up to complete secondary education - but without college. Unskilled labor is further divided into high school graduates and those without a high school diploma - also referred to as "dropouts" in the analysis.

These wage premiums are estimated by means of a Mincer wage regression based on individual worker's microdata. The Mincer equation consists of a regression of the logarithm of the hourly wages on dummies for educational levels, a potential experience variable (constructed as age minus years of education minus 6) and its powers up to the order of 4, and a series of regional and urbanrural controls. The remuneration for each input $\left(\ln w_{k t}\right)$ is computed from this regression as a weighted average of the returns to education of each of the educational levels belonging to the corresponding input. The wage premiums are then obtained as the difference of these remunerations. These regressions have the following form:

$$
\ln w_{i t}=\alpha+\beta_{\text {c.coll } t} D_{\text {c.coll } t}+\beta_{\text {i.coll } t} D_{\text {i.coll } t}+\beta_{\text {c.sec } t} D_{\text {c.sec } t}+\beta_{\text {i.sec } t} D_{\text {i.sec } t}+\beta_{\text {c.prit } t} D_{\text {c.pri } t}+\delta X_{i t}+\varepsilon_{i t}
$$

where $w$ is the wage for worker $i$ at time $t$, the $D$ variables are indicators for the level of educational attainment (college complete and incomplete, secondary complete and incomplete, and primary complete - primary incomplete is the omitted category) with their corresponding $\beta$ coefficients, and the $X$ variables represent a set of individual characteristics, which include years of experience, region of residence and urban/rural status (when available). 
Defining skilled workers as those with some college (complete or incomplete) and the unskilled as those without any college education, the corresponding skilled-unskilled wage premium is given by:

$$
\ln \left(\frac{w_{S t}}{w_{U t}}\right)=\left[\gamma_{\text {c. coll }} \beta_{\text {c.coll } t}+\gamma_{\text {i.coll }} \beta_{\text {i.collt } t}\right]-\left[\gamma_{\text {c.sec } U} \beta_{\text {c.sect } t}+\gamma_{\text {i.sec } U} \beta_{\text {i.sect } t}+\gamma_{\text {c.priU }} \beta_{\text {c.prit } t}\right]
$$

where $\beta_{i t}$ is the coefficient associated to educational level $i$ in the Mincer equation at time $t$, and $\gamma_{i k}=$ $E_{i} / E_{k}$ is the share of employment of the individuals with the educational level $i$ in the employment of input $k$ in a base period. ${ }^{21}$

Analogously, the high school-dropout wage premium or differential can be obtained as:

$$
\ln \left(\frac{w_{H t}}{w_{D t}}\right)=\beta_{\text {c.sec } t}-\left[\gamma_{\text {i.sec } \mathrm{D}} \beta_{\text {i.sect } t}+\gamma_{\text {c.priD }} \beta_{\text {c.prit }}\right]
$$

To sum up, the remuneration for each type of work (skilled and unskilled) is obtained as a weighted average of the returns to education of each educational level, where the weights are given by the proportion of individuals with the corresponding educational level, and the wage premiums are obtained as the ratio of these remunerations (in logs). These two variables are based on six educational levels included in the Mincer regression: complete college (c.coll), incomplete college (i.coll), complete secondary (c.sec), incomplete secondary (i.sec), complete primary (c.pri) and incomplete primary, the excluded category.

\section{B3. Construction of relative supplies}

The relative supplies are also computed from individual microdata from the sixteen countries in our sample. We use the working age population as a basis for the relative labor supplies, although the trends described in this paper are qualitatively the same if instead of using the population we construct our measures of relative supply, as in Manacorda et al. (2010), based on the labor force, those in employment or hours of work.

The relative supplies represent a weighted sum of individuals in each of the three skill categories defined above. Following Katz and Murphy (1992) and Goldin and Katz (2007), we first compute efficiency units for each country dividing the population into 24 groups (cells) according to their gender, educational level and potential experience. ${ }^{22}$ For each cell, we compute the average wage for all years with respect to the wage of the largest group in the last year of the sample. These relative wages constitute the factors used to weight the supply for each cell in efficiency units, and the supply for high school dropouts, high school graduates and those with some tertiary education is simply the sum of the supplies of the individual cells (in efficiency units). For skilled labor, for instance, it is the sum of the supplies of the cells with individuals with some college education. Finally, the relative supplies are computed as the ratios of each input's supply. ${ }^{23}$

\footnotetext{
21 As in Katz and Murphy (1992), the base period is defined here as the average of all years for each country.

${ }^{22}$ Four educational levels (complete college, incomplete college, complete secondary and less than complete secondary) and three groups of potential experience ( 0 to 15 years, 16 to 30 years, and more than 30 years) are considered.

${ }^{23}$ In the figures below, we express this relative supplies in log terms.
} 


\section{B4.Construction of relative demands}

A residual relative demand can be computed from these relative supplies and premiums. As shown by Katz and Murphy (1992), under perfect competition and considering a CES technology with two factors (skilled and unskilled workers), the relative wages in year $t, w_{S t} / w_{U t}$, and relative supplies in year $t, \mathrm{~S}_{t} / \mathrm{U}_{t}$, satisfy the relationship:

$$
\ln \left(\frac{w_{S_{t}}}{w_{U_{t}}}\right)=\left(\frac{1}{\sigma}\right)\left[D_{t}-\ln \left(\frac{S_{t}}{U_{t}}\right)\right]
$$

where $\sigma$ is the elasticity of substitution between skilled and unskilled workers and $\mathrm{D}_{t}$ is the time series of relative demand shifts measured in log quantity units. Under the assumption that the economy operates on the demand curve given by this equation, we can obtain a time series of relative demand between skilled and unskilled workers for a given value of the elasticity of substitution between factors $\sigma_{0}$ :

$$
D_{t}=\sigma_{0} \ln \left(\frac{w_{S_{t}}}{w_{U_{t}}}\right)+\ln \left(\frac{S_{t}}{U_{t}}\right)
$$

Similarly, we can obtain a measure of relative demand for high school-dropouts workers assuming different values of $\sigma_{0}$. According to the results for Latin American countries in Manacorda et. al (2010), we use their estimated value of the elasticity of substitution between skilled and unskilled workers $\left(\sigma_{0} \approx 3\right)$ as an input in our calculations of relative demands. Also, we use alternative values of this parameter as a robustness check. 


\section{C.Appendix: Evolution of relevant variables over time by country}

The main body of this document constructs a story based on the common trends for 16 Latin American countries. An aggregate analysis of this type, however, is necessarily based on generalizations and simplifications. This appendix presents a country by country depiction of the evolution over time and of the relationship between some of the variables of interest in the analysis, and thus provides the basis for qualifications and clarifications to the aggregate trends discussed in the main body of the document.

\section{C1.Wage premiums, relative supply and relative demand: Country- specific trends}

The first row of Table 3.1 details the differential evolution of the labor market in the decades of 1990 and 2000 for Argentina. The wage premium slightly decreased between 1986 and 1992, substantially increased in the 1990s, and then fell over most of the 2000s. The relative supply of skilled labor grew fast, at around 3.5 percent in the 1980s, 5 percent in the 1990s and continued growing in the 2000s, although at a slower pace. These patterns are consistent with a small positive shift in the relative demand for skilled labor in the 1980s and a very large increase in the 1990s. This evidence for the decade of 2000 points to a fall in the relative demand for skilled labor, which should have contributed to the fall in the wage premium, along with the continuing increase in the relative supply. The first row of Table 3.2, in turn, details the evolution of the corresponding variables within the group of unskilled workers for Argentina. While the whole period saw a continuous increase in the relative supply of skilled labor, within the unskilled the relative increase in the supply of workers with secondary education was quantitatively significant only for the decade of 2000, with an increase of 6.8 percent per year. The relative remuneration of the high school graduates group remained virtually unchanged in the 2000 s despite the very large increase in its relative supply, indicating the presence of a strong demand for this type of labor that neutralized the negative impact of increasing supply. ${ }^{24}$

The results for Bolivia are presented in the following rows of Tables 3.1 and 3.2 - because of data source limitations, the 1990s in this case represents only the period from 1997 to 2000, and the 2000s from 2000 to 2007 . The evolution of the aggregate wage skill premium indicates a large increase in 1997-2000 and a large fall in 2000-2007, with positive changes in the supply only in the latter period. The growing wage skill premium in the late 1990s seems to be driven by a strong increase in the relative demand for skilled labor, while the story for the 2000s emerging from this table is substantially different, and similar to that of other Latin American countries. Falling wage gaps between the more educated and the rest are consistent with a robust increase in the relative supply of skilled labor and a concurrent fall in its relative demand. Meanwhile, the evolution of the relative remuneration within the group of the unskilled, presented in Table 3.2, indicates a substantial fall in the wage premium of the high school graduates for 1997-2000, and a small decrease for 2000-2007,

\footnotetext{
${ }^{24}$ Gasparini and Cruces (2010) present a detailed study and a review of the literature for Argentina of the plausible factors behind these changes in the relative demand for skilled labor over the period 1974-2006.
} 
while the relative supply of this group increased significantly over the two decades, with a stronger increase in the 2000s. This is consistent with a weak pattern of relative demand for workers with medium skill levels during 1997-2000 (so that the increase in supply reduced their relative wage), and a substantial increase in their relative demand afterwards, as witnessed by the small change in the corresponding wage premium in the context of a large increase in its relative supply.

The evolution of the wage skill premium in Brazil, meanwhile, shows a slow decline in the 1990s, and after a small increase in the turn of the century, a strong decline that intensified since 2006 (see the corresponding Figure $\mathrm{C} 1$ in the appendix). The strong increase in the relative supply of skilled labor, which accelerated in the 2000s, seems to have played a relevant role in the Brazilian case. The relative demand for skilled labor consistent with these patterns of premium and supply indicates a stable trend in the 1990s and a fall in the 2000s. Meanwhile, as depicted in Table 3.2, the relative supply of workers with secondary education with respect to lower skilled workers increased substantially over the two periods considered. This growth pattern accelerated in the $2000 \mathrm{~s}$ : it grew at a faster pace than the increase in the relative supply of the high skill group. The relative wage of the middle skill group fell over the two periods at an increasing rate, and seems to have broadly followed from the evolution of its relative supply. The decade of 2000 was the period with the largest increase in the relative supply of the high and middle skill groups, and the evolution of the wage premium for both groups indicates that demand factors were not enough to compensate for their increasing supply.

The evolution of these variables for Chile in Table 3.1 reveals an increase in the wage gap between the skilled and the unskilled in the 1990s, and after a short plateau, a fall throughout the 2000s. The relative supply of skilled workers increased over the two decades, although at a slower pace in the 2000s. These patterns of wages and supply are consistent with a strong increase in the demand for skilled labor in the 1990s and a fall in the 2000s. ${ }^{25}$ The pattern for the high school-dropout relative remuneration, presented in Table 3.2, is similar to the evolution of the aggregate wage skill premium: it increased slightly over the 1990-2000 decade, and fell significantly (-1.8 per year on average) for the 2000-2009 period. The main difference with the aggregate skilled-unskilled trend is the evolution of the relative supply: workers with secondary education increased substantially for both decades, and the relative change of the high school group with respect to dropouts was larger than the relative increase for the higher skill group. This pattern indicates the presence of an increasing relative demand for workers with secondary education in the 1990s, which counterbalanced the negative effect of the increase in their supply on the corresponding wage premium, and a lower impact of demand factors for this group in the following decade.

The household surveys in Colombia have changed substantially over the period under analysis, posing substantial challenges for the analysis of patterns over time. Table 3.1 and 3.2 report changes in these variables for two episodes for which surveys are comparable to a reasonable degree - 1996 to 2000 and 2001 to 2007 . During the first period, the wage skill premium became substantially larger, despite a strong increase in the relative labor supply of skilled workers. This combination suggests a strong increase in the relative demand for skilled labor. In contrast, the 2000s have

\footnotetext{
25 The pattern of a roughly constant wage skill premium and sizeable increase in the relative supply of skilled labor in the 1990s, and the conclusion on the relevance of changes in the relative demand for this factor over the decade, coincide with the findings of Gallego (2011), who uses a longer data series that covers only the Greater Santiago metropolitan area.
} 
witnessed a fall in the wage premium. Given that the relative supply of this group continued growing at a substantial rate, the relative demand must not have changed significantly. The evidence for Colombia in Table 3.2 indicates the presence of stronger relative demand forces for high school workers in the 1990s than in the 2000s. The wage premium fell very little in the context of a large increase in the relative supply of workers with secondary education in 1996-2000, while with an expansion rate of about half that in the previous period the wage premium fell substantially more, indicating a shift in the relative demand towards this group with respect to workers without a high school degree.

The results for Costa Rica in Table 3.1 indicate that the relative supply of skilled workers in Costa Rica increased at an annual rate of 4 percent in the 1990s, and of 3.4 percent in the 2000s. Although Figure $\mathrm{C} 1$ in the appendix below indicates substantial fluctuations over the period, the wage gap increased slightly in the 1990s, in particular at the end of the decade. The wage premium fell between 2002 and 2005 but started to increase again in the second half of the decade. Nevertheless, the overall change 2002-2009 is negative, although small. Given the increase in the relative supply, this small change is consistent, given the assumed elasticities of substitution, with a small positive shift in relative demand, smaller than in the 1990s. Table 3.2, in turn, indicates that the relative supply of semi-skilled workers (with respect to high school dropouts) increased in both periods at an accelerating rate, with relatively minor changes in the high school skill premium - negative in the 1990s and positive in the 2000s. A notable difference in the case of Costa Rica is that the relative increase of the high skill group was larger than that of the middle skill group. The evidence indicates the presence of stronger relative demand forces for high school graduate workers in 2002-2009 than in the 1990-2002 period: demand factors must have operated in the most recent years, since the relative wage of high skill workers increased moderately with simultaneous increase in its relative supply.

Data limitations in the case of Ecuador restrict the comparability of the available surveys from the 1990s with those of the 2000s. The analysis here is based on comparable statistics constructed for the 2000s, based on the ENEMDU survey. The wage skill premium fell at an annual rate of 3.2 percent between 2003 and 2010, while the relative supply increased steadily in the same period. This indicates that, conditional on the assumptions on elasticities of substitution, the relative demand for skilled labor must have fallen over that period. With respect to unskilled workers, the increase in the relative supply of the high school group resulted in a reduction of its wage premium over the 20032010 period. This pattern is similar to that of the aggregate skilled-unskilled premium and relative demand, although the changes are smaller for the high school-dropout differentials. As in the cases of Colombia and Costa Rica, Tables 3.1 and 3.2 indicate that most of the reduction in the share of employment of the low skill group was accounted for by an increase of that of the high skill group, although, as discussed in the sector decompositions section, in the case of Ecuador there were relatively large within and between sector effects for both skill groups.

Table 3.1 indicates that the relative supply of skilled labor increased strongly in El Salvador during the 1990s. The corresponding wage premium also increased significantly during that decade, and these simultaneous trends are consistent with a strong increase in the relative demand for skilled labor. The evolution of these variables in the decade of 2000, however, indicates a marked change. The relative labor supply of skilled labor stopped growing, while the corresponding wage premium 
fluctuated wildly - in 2007 it stood roughly at the same level as in 2001. These patterns are consistent with a volatile, but roughly constant relative demand for skilled labor over this period. The evolution of the high school-dropout wage premium and relative supply in Table 3.2, in turn, signals the presence of substantial demand forces for this middle education group for the two decades, since despite large increases in the relative supply the wage differential fell relatively little.

The evolution of supplies and premiums from Honduras reveal a great deal of volatility, in part due to changes in the underlying household survey. Table 3.1 shows that the relative supply for skilled labor increased over the two decades, with virtually no change in the wage skill premium in the 1990s indicating a relative demand for skilled labor growing at the same rate as its relative supply. In the 2000s, however, the fall in the wage premium is consistent with a slow or even decreasing relative demand for this factor. Table 3.2, meanwhile, indicates that the high school-dropout wage differential fell by 1.8 percent per year over the decade of 1990 , with a small concurrent increase in its relative supply over the same period. For the decade of 2000, the corresponding wage premium only exhibits a small increase, but with a substantially larger reduction in the relative supply of high school graduates. Both patterns are consistent with a decrease in the relative demand for this type of labor over the two periods. It should be noted that this fall in the relative supply of high school graduates is one of the few observed for the countries and periods under analysis.

Table 3.1 and the evolution of the underlying variables (see the Appendix below) indicates that the wage premium increased substantially in Mexico in the late 1980s and early 1990s, even when ignoring the hike around 1995 (the "Tequila" financial crisis). The fall in the wage premium that characterized most of the Latin American economies in the 2000s started in Mexico a few years earlier, in the late 1990s, and accelerated in the next decade. The increase in the relative supply of skilled labor was strong throughout the whole period, especially in the 1990s. The increase in the wage premium and the relative supply of skilled labor in the 1990s is consistent with a strong increase in its relative demand. ${ }^{26}$ On the other hand, the assumed elasticities of substitution indicate that the fall in the wage premium during the decade of 2000 and the deceleration in the growth of its relative supply call for a reduction in the relative demand of skilled labor in this decade. When studying the underlying trends within unskilled workers, there was a substantial increase in the relative supply of high school graduates (of about 4.6 percent a year on average) during the 1990s, with a corresponding fall in the relative wage premium for this group (with respect to those with no secondary degree) of -1.5 percent. The following decade (2000-2008), however, is marked by the stagnation (a small fall) in the relative supply of workers from the high school group, accompanied also by reduction in its wage differential. This pattern is consistent with the presence of negative relative demand forces for this factor during the 2000 s.

Nicaragua has carried out few national household surveys in the last two decades, although these sources are comparable and allow the construction of a coherent story. The results in Table 3.1 indicate that the relative supply of skilled labor strongly rose over the two decades, starting from very low levels. The conditional wage gap between skilled and unskilled labor increased sharply in the 1990s, and then fell in the 2000s. These movements are consistent with a strong increase in the relative demand for skilled labor in Nicaragua in the 1990s and a subsequent fall in the 2000s. The country also experienced a substantial increase in the relative supply of high school workers, of 2.1

\footnotetext{
${ }^{26}$ Montes Rojas (2006) carries out a similar type of analysis for Mexico and shares this conclusion.
} 
percent per year on average for the period 1993-2001 and 4 percent per year for 2001-2005. In contrast with the large positive and negative changes in the aggregate skilled-unskilled wage premium observed for the two periods, the high school-dropout relative remunerations exhibit very small negative changes. This pattern is consistent with positive demand shifts for the middle skill group over both periods.

The evidence for Panama in Table 3.1 indicates that the relative labor supply of skilled labor has been increasing at almost the same rate over the two decades considered in this document (see Galiani, 2009, for a longer term analysis of Panama using data from the 1980s onwards). However, while the wage premium increased slightly in the 1990s, it fell in the 2000s, calling for different patterns in the relative demand for skills - increasing in the 1990s and falling in the 2000s. Table 3.2 in turn presents the decomposition for unskilled workers over the periods 1992-2001 and 2001-2009. The relative supply of workers with secondary education increased substantially in Panama both during the 1990s (about 3 percent per year) and the 2000s (about 5 percent per year), with only relatively small reductions in the corresponding wage differential $(-1.2$ percent and -0.7 percent, respectively), suggesting the presence of strong countervailing positive demand for this group in the labor market.

Comparable data for Paraguay is only available since 1997, although some comparability problems persist -this is apparent in the volatility of the variables, as depicted in Figure $\mathrm{C} 1$ in the appendix. As in other countries of the region, Table 3.1 indicates that the wage premium seems to have increased in the late 1990s, and substantially fallen since the macroeconomic crisis of the early 2000s. Since the relative supply of skilled labor strongly increased over the period, a compatible trend for the relative demand means that it should have also strongly increased in the 1990s, and likely fallen in the 2000s. The results in Table 3.2 signal that the relative supply of high school workers increased substantially over the 1997-2003 (2. 6 percent per year) and 2003-2009 (5.9 percent per year) periods. The increase in the relative supply in the late 1990s was accompanied by a relatively small fall in the corresponding wage differential, suggesting some compensating increase in the relative demand for this factor. However, these demand forces do not seem to have been operational over the 2003-2009 period, during which the high school-dropout wage premium fell substantially. It should be noted that the pattern of the high school/dropout wage premium and relative supply is qualitatively similar to that of the aggregate skilled-unskilled differences.

As in the case of Paraguay, comparable data for Peru is only available since 1997 and some comparability issues persist. The trends summarized in Table 3.1 point towards differential trends for the two decades under consideration: an increase in the wage premium in the 1990s, and a fall in the 2000s, in particular after 2006 (see Figure C1 below). There was a simultaneous increase in the relative supply of skilled labor in both periods, although it was more slightly more intense in the 2000s. These patterns are consistent with a strong increase in the demand for skilled labor in the 1990 s and a subsequent fall in the 2000s. Table 3.2 in turn presents the high school-dropout results. For both the 1997-2003 and 2004-2009 periods, there is a steady increase in the relative supply of the high school group, but this is accompanied in the first period by a modest increase in the corresponding wage premium and by a substantial fall for 2004-2009. These results are consistent with the presence of a strong increase in the relative demand for this factor over the 1997-2003 period. 
The results for Uruguay in Table 3.1 indicate that the wage premium increased substantially in the 1990 s, and started to fall after the macroeconomic crisis of the early 2000s. The relative labor supply of skilled labor increased over the two decades, although at a slower rate in the 2000s. These patterns are consistent with a large positive shift in the relative demand for skilled labor in the 1990s, while for the 2000s the evidence points to a fall in the relative demand for this factor, which contributed (along with a stagnant supply) to the fall in the wage premium.

Finally, Table 3.1 indicates the presence of a small increase in the skilled-unskilled wage premium in Venezuela in the late 1990s, and a significant fall in the 2000s. The relative supply of skilled labor grew over the two decades, and the effects of the increase was likely offset by a larger increase in relative demand in the $1990 \mathrm{~s}$, resulting in the increasing wage premium. For the $2000 \mathrm{~s}$, on the contrary, the pattern of increasing relative supply and falling wage premium indicates the presence of a reduction in the relative demand. Table 3.2 , in turn, shows that the relative supply of high school graduates also increased significantly over the periods 1995-2002 (about 3 percent per year) and 2002-2006 (7.6 percent per year on average). The corresponding wage premium, however, remained virtually unchanged during the first period, suggesting the presence of a compensating increase in the relative demand for the factor. The wage premium for 2002-2006 fell substantially, probably as a consequence of the expansion in the relative supply of high school graduates and a change in the pattern of demand for this factor. 


\section{C2.Wage premiums and relative supplies: evolution and scatter plots by country}

\section{Figure C1}

Skilled-unskilled wage skill premium and relative supply over time

Deviations from each country's mean

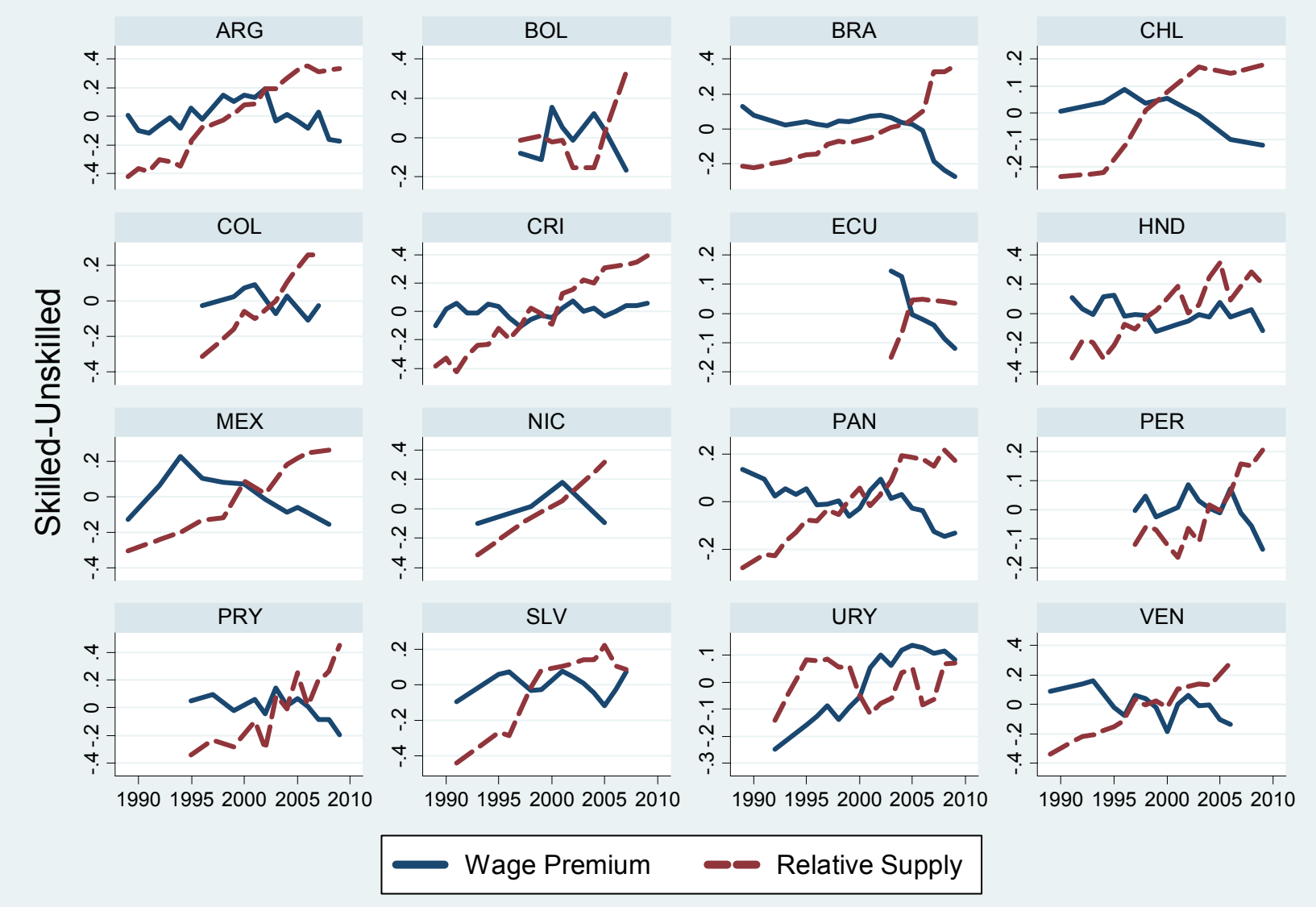

Source: own computations based on SEDLAC (CEDLAS and World Bank). 
Figure C2

High school-dropouts wage skill premium and relative supply over time

Deviations from each country's mean

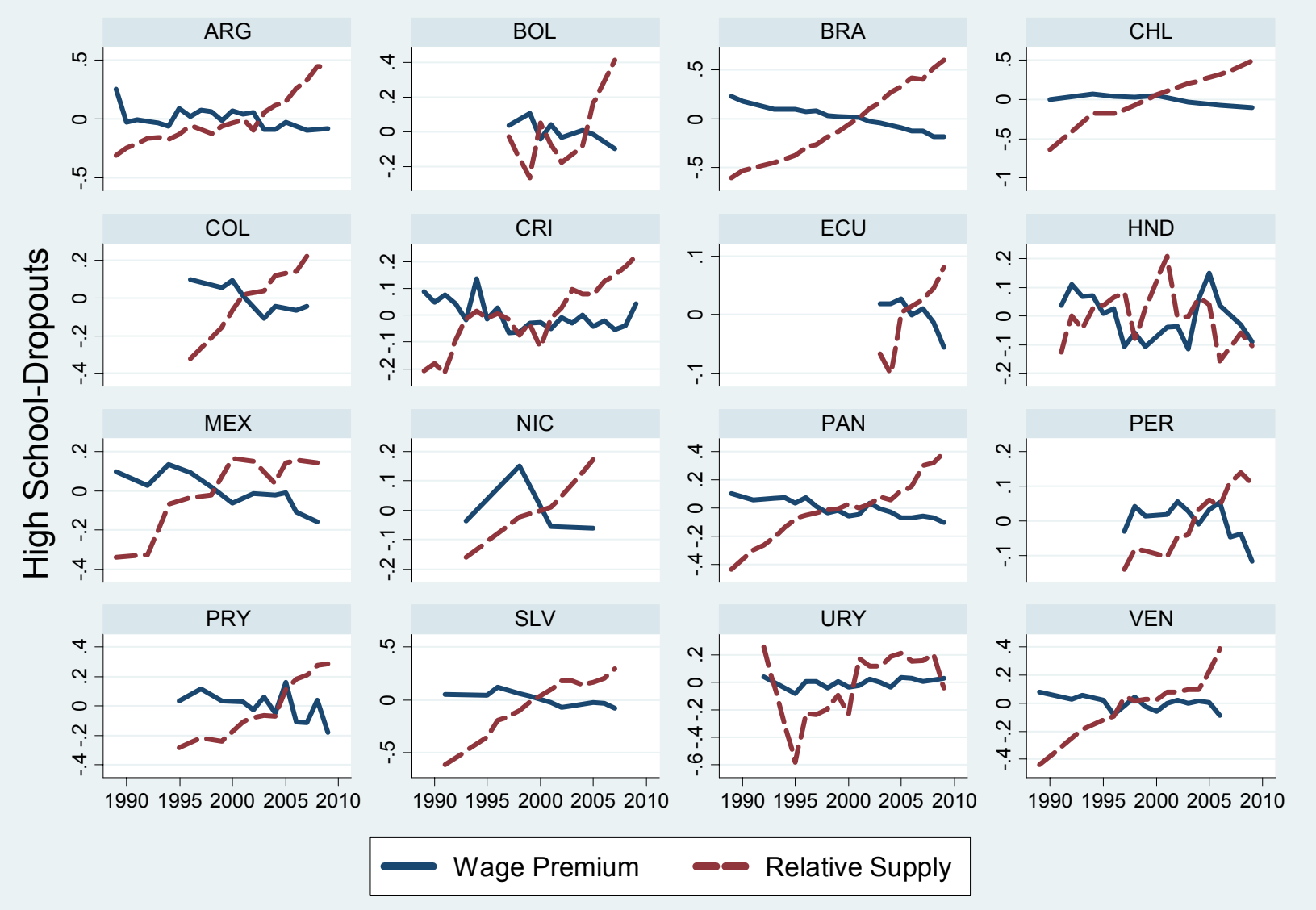

Source: own computations based on SEDLAC (CEDLAS and World Bank). 
Figure C3

Skilled-unskilled wage skill premium and relative supply
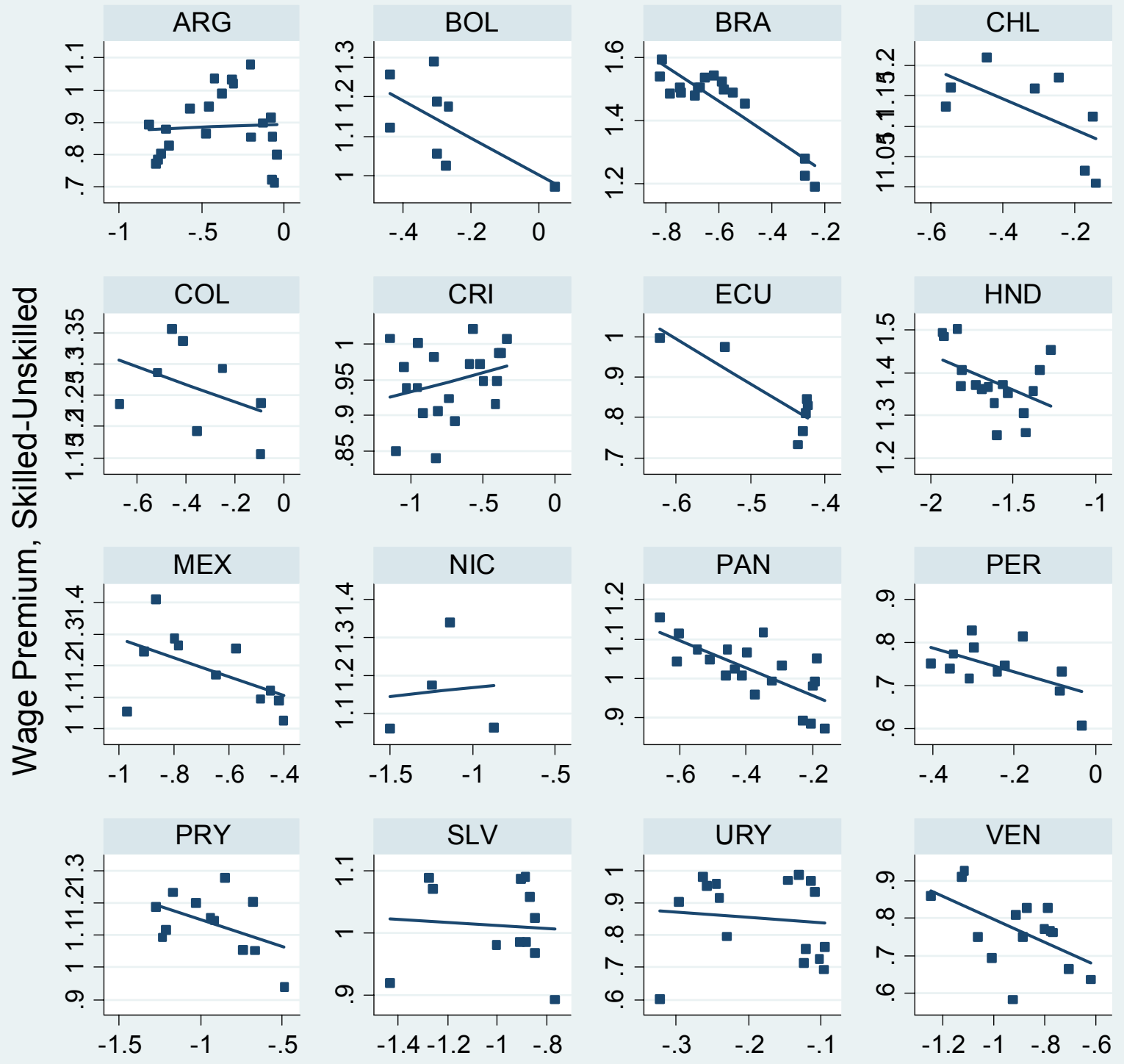

Relative Supply, Skilled-Unskilled

Source: own computations based on SEDLAC (CEDLAS and World Bank). 

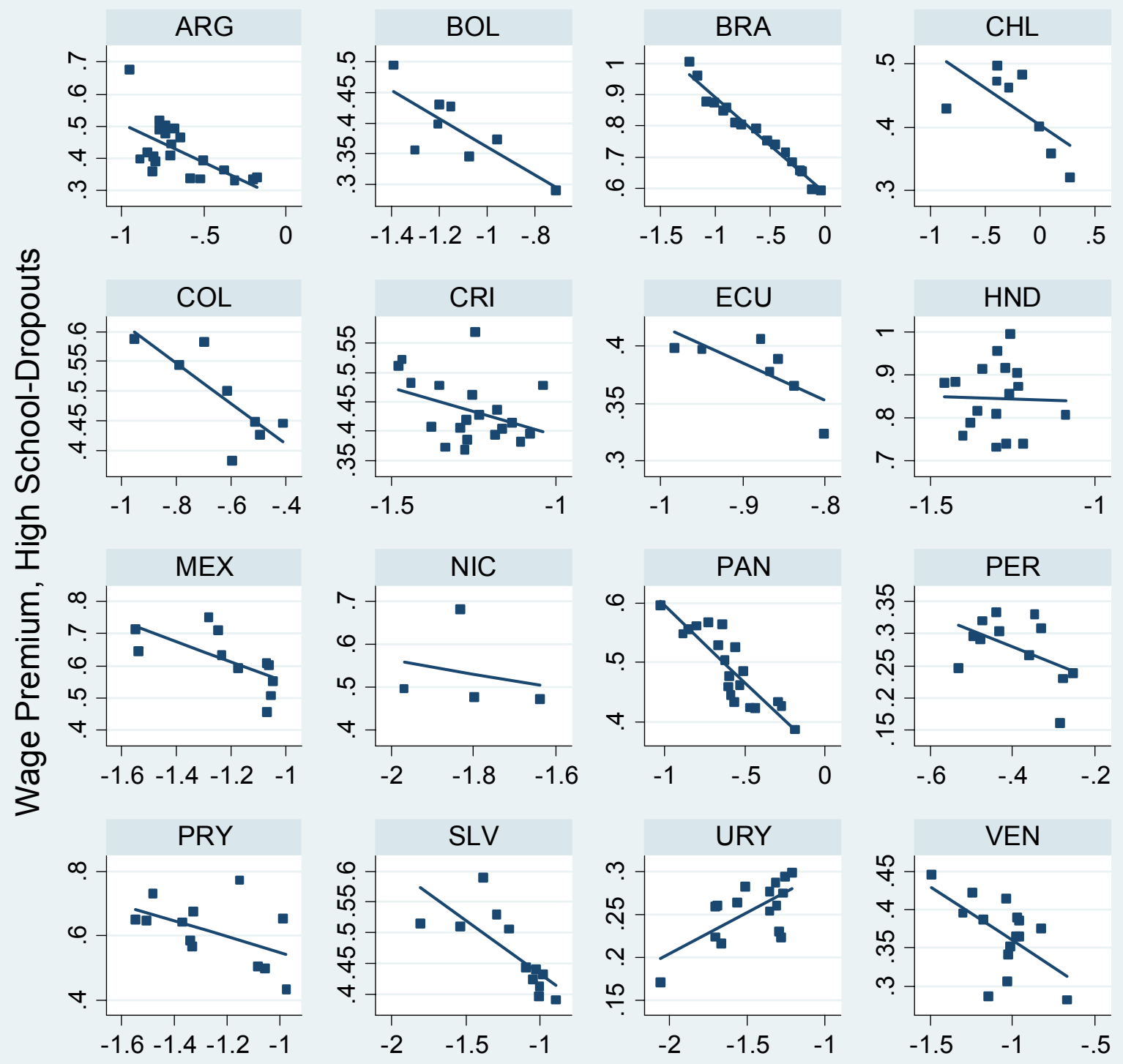

Relative Supply, High School-Dropouts

Source: own computations based on SEDLAC (CEDLAS and World Bank). 


\section{C3.Wage skill premiums and terms of trade: evolution and scatter plots by country}

Figure C5

Wage skill premiums and terms of trade over time

Deviations from each country's mean
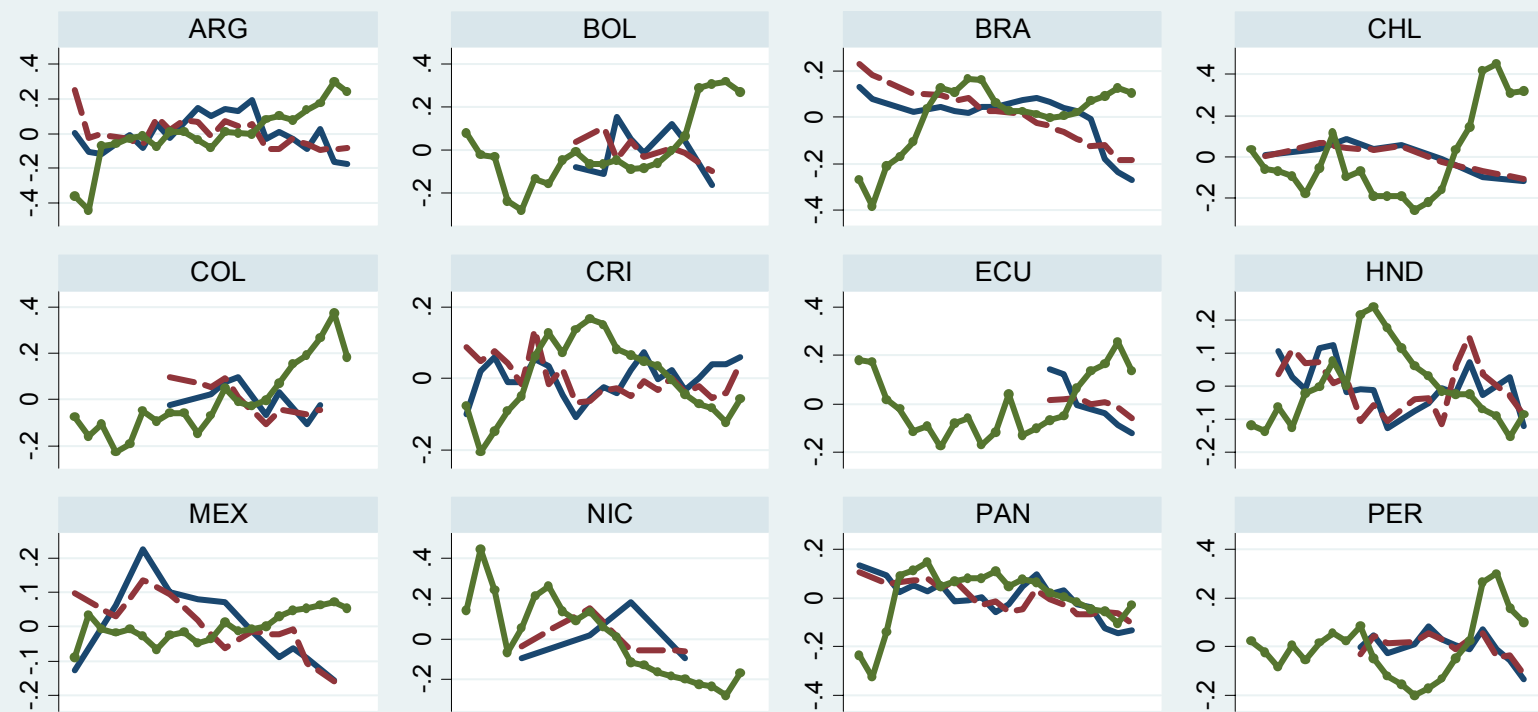

$\mathrm{NIC}$
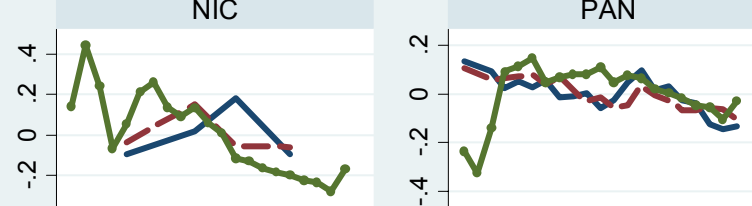

PER
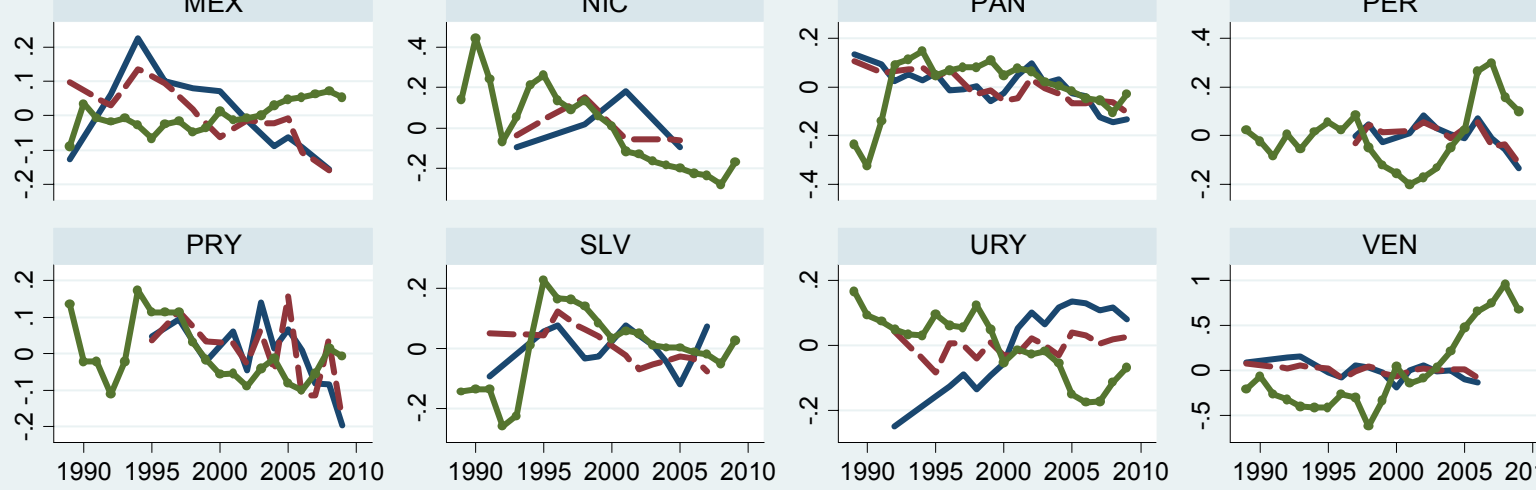

VEN

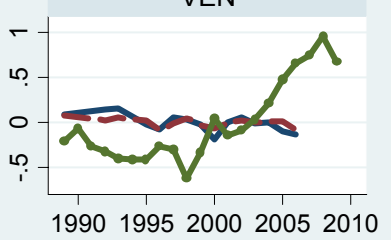

Wage Premium S-U

Wage Premium H-D

Log Terms of Trade Index

Source: own computations based on SEDLAC (CEDLAS and World Bank) and World Development Indicators. 
Figure C6

Skilled-unskilled wage skill premium and terms of trade
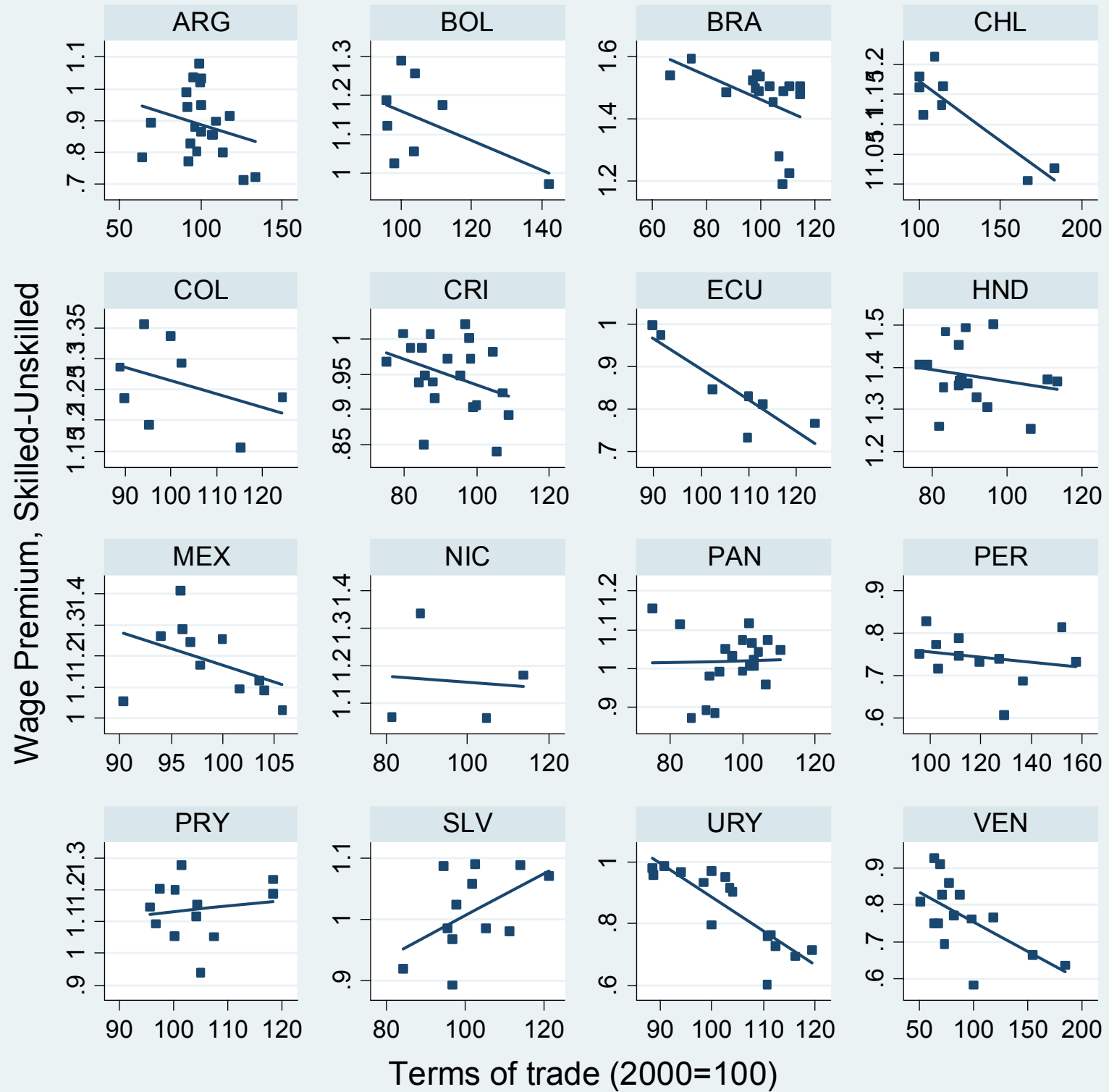

Source: own computations based on SEDLAC (CEDLAS and World Bank). 
Figure C7

High school-dropouts wage skill premium and terms of trade
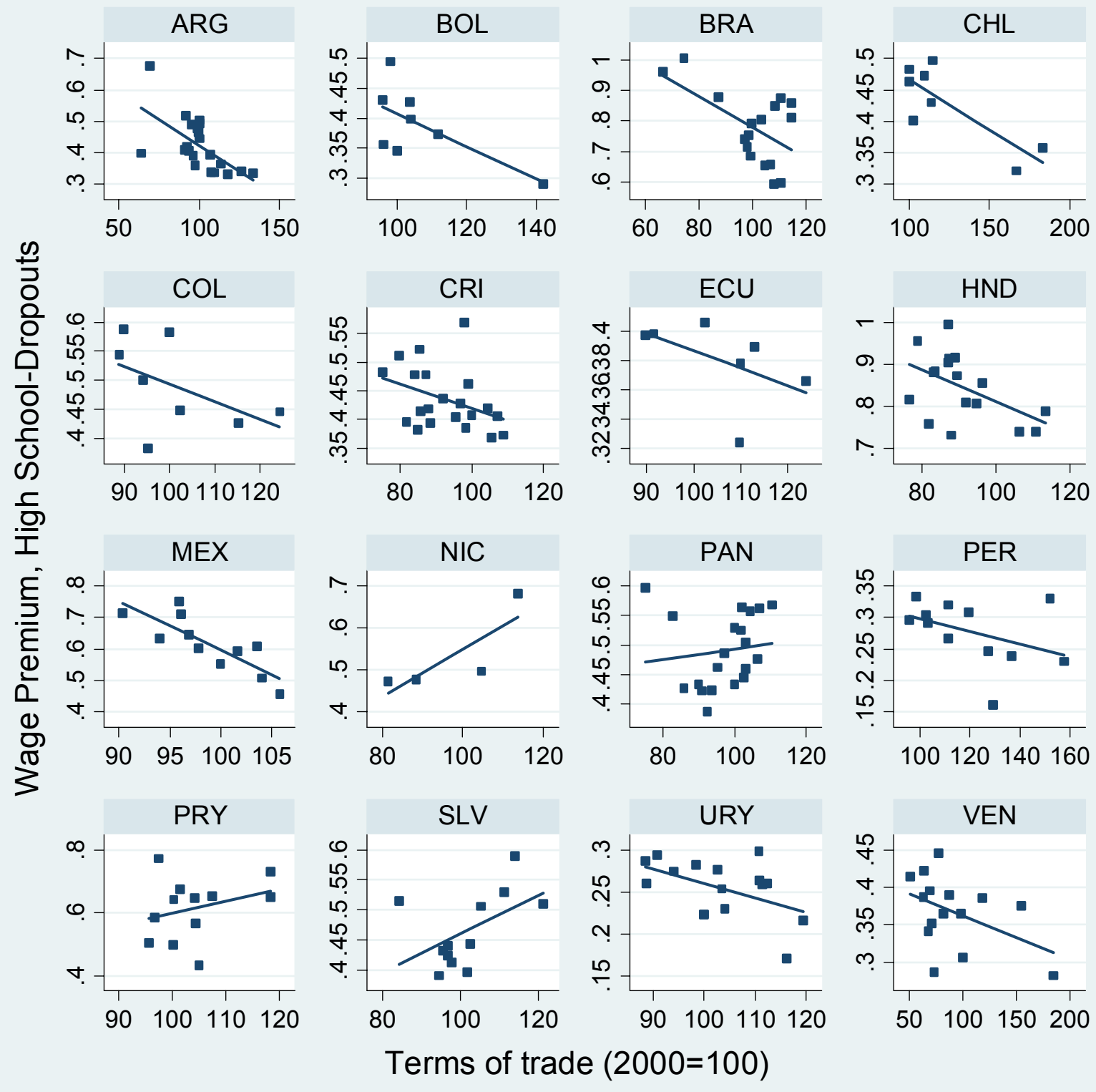

Source: own computations based on SEDLAC (CEDLAS and World Bank). 